\title{
Microscopic (Dis)order and Dynamics of Cations in Mixed FA/MA Lead Halide Perovskites
}

\author{
Published as part of The Journal of Physical Chemistry virtual special issue "Hellmut Eckert Festschrift". \\ Helen Grüninger,* Menno Bokdam,* Nico Leupold, Paul Tinnemans, Ralf Moos, Gilles A. De Wijs, \\ Fabian Panzer, and Arno P. M. Kentgens*
}

Cite This: J. Phys. Chem. C 2021, 125, 1742-1753

Read Online

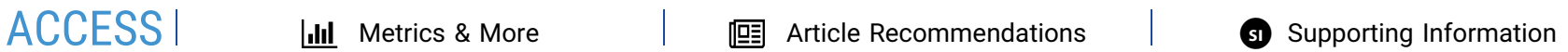

ABSTRACT: Recent developments in the field of high efficiency perovskite solar cells are based on stabilization of the perovskite crystal structure of $\mathrm{FAPbI}_{3}$ while preserving its excellent optoelectronic properties. Compositional engineering of, for example, $\mathrm{MA}$ or $\mathrm{Br}$ mixed into $\mathrm{FAPbI}_{3}$ results in the desired effects, but detailed knowledge of local structural features, such as local (dis)order or cation interactions of formamidinium (FA) and methylammonium (MA), is still limited. This knowledge is, however, crucial for their further development. Here, we shed light on the microscopic distribution of $\mathrm{MA}$ and $\mathrm{FA}$ in mixed

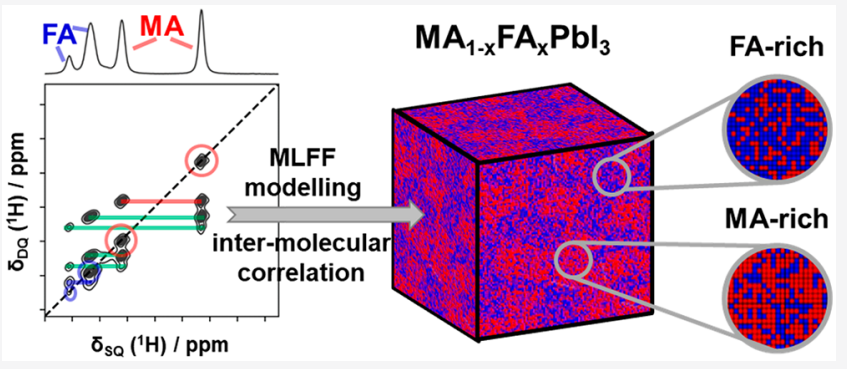
perovskites $\mathrm{MA}_{1-x} \mathrm{FA}_{x} \mathrm{PbI}_{3}$ and $\mathrm{MA}_{0.15} \mathrm{FA}_{0.85} \mathrm{PbI}_{2.55} \mathrm{Br}_{0.45}$ by combining high-resolution double-quantum ${ }^{1} \mathrm{H}$ solid-state nuclear magnetic resonance (NMR) spectroscopy with state-of-the-art near-first-principles accuracy molecular dynamics (MD) simulations using machine-learning force-fields (MLFFs). We show that on a small local scale, partial MA and FA clustering takes place over the whole MA/FA compositional range. A reasonable driving force for the clustering might be an increase of the dynamical freedom of FA cations in FA-rich regions. While $\mathrm{MA}_{0.15} \mathrm{FA}_{0.85} \mathrm{PbI}_{2.55} \mathrm{Br}_{0.45}$ displays similar $\mathrm{MA}$ and $\mathrm{FA}$ ordering as the $\mathrm{MA}_{1-x} \mathrm{FA}_{x} \mathrm{PbI}_{3}$ systems, the average cation-cation interaction strength increased significantly in this double mixed material, indicating a restriction of the space accessible to the cations or their partial immobilization upon $\mathrm{Br}^{-}$incorporation. Our results shed light on the heterogeneities in cation composition of mixed halide perovskites, helping to exploit their full optoelectronic potential.

\section{INTRODUCTION}

Over the past decade, lead halide perovskites have attracted great interest due to their potential application in solar cells, with excellent power conversion efficiencies of currently up to 25.5\%. ${ }^{1}$ Other efficient perovskite-based optoelectronic devices, such as light-emitting diodes and X-ray detectors, were demonstrated as well. ${ }^{2-6} \mathrm{~A}$ key aspect is the simplicity of tuning the composition of halide perovskites, which makes it possible to adapt their structural and optoelectronic properties, such as phase transitions, band gap energy, as well as chargecarrier lifetimes and mobilities, ${ }^{7-11}$ to achieve desired properties for the different applications. Halide perovskites typically have an $\mathrm{APbX}_{3}$ composition, in which $\mathrm{Pb}^{2+}$ forms corner-sharing $\mathrm{PbX}_{6}$ octahedra with $\mathrm{X}$ being a halide $\left(\mathrm{X}=\mathrm{Cl}^{-}\right.$, $\mathrm{Br}^{-}$, or $\left.\mathrm{I}^{-}\right){ }^{8,12,13}$ The dodecahedral A site is occupied by a monovalent cation, typically methylammonium $\left(\mathrm{CH}_{3} \mathrm{NH}_{3}{ }^{+}\right.$, $\mathrm{MA})$, formamidinium $\left(\mathrm{CH}_{3}\left(\mathrm{NH}_{2}\right)_{2}{ }^{+}, \mathrm{FA}\right)$, or $\mathrm{Cs}^{+} .{ }^{12,14}$ The first efficient perovskite solar cells were realized using ternary halide perovskites, especially $\mathrm{MAPbI}_{3}$, before a further increase in efficiencies above $20 \%$ was achieved on the basis of mixed multinary halide perovskites, ${ }^{15,16}$ such as a "triple cation" perovskite of the form $\mathrm{MA}_{x} \mathrm{FA}_{0.95-\mathrm{x}} \mathrm{Cs}_{0.05} \mathrm{~Pb}\left(\mathrm{I}_{1-\mathrm{y}} \mathrm{Br}_{y}\right)_{3}{ }^{17}$ However, these highly alloyed perovskites show phase segregation especially under illumination, ${ }^{18,19}$ limiting their optoelectronic performance and long-term stability. ${ }^{20,21}$ In recent years, the highest perovskite solar cell efficiencies of $>23 \%$ were achieved with perovskites that again have a less complex stoichiometry, e.g., double cation perovskites ${ }^{17}$ or even simple $\mathrm{FAPbI}_{3} \cdot{ }^{22,23}$ The latter requires stabilization into its optoelectronically desired $\alpha$-phase, ${ }^{24-26}$ which can be achieved by adding a second cation, e.g., MA. ${ }^{26-28}$ Upon incorporation of MA in FA-based perovskites, the Goldschmidt tolerance factor is better fulfilled, ${ }^{29}$ decreasing strain within the structure and thus improving charge transport properties. ${ }^{30,31}$

Received: November 6, 2020

Revised: December 31, 2020

Published: January 15, 2021 
This recent progress has made it very clear how extremely sensitive the optoelectronic performance and stability of halide perovskites are with respect to their stoichiometry and compositional microstructure. ${ }^{9,32-37}$ Developing a fundamental understanding of structure-property relations is crucial to further advance perovskite-based optoelectronic devices. Even though the mixing behavior of A cations in the perovskite structure was the focus of various works in the past, ${ }^{26,38-43}$ a complete understanding of the microstructure of A cation mixtures is not yet established.

Nuclear magnetic resonance (NMR) spectroscopy provides an accurate probe of the local environment of different functional groups embedded in the crystal structure. NMR spectroscopy of perovskites has proven valuable to accurately probe the cation ratios of mixed compositions, halide order and disorder, halide or cation phase segregation, and cation dynamics. $^{25,26,42,44}$ Organic A cation mixtures can be analyzed in terms of types, ratios, and dynamics by high-resolution ${ }^{1} \mathrm{H}$, ${ }^{13} \mathrm{C}$, and ${ }^{14} \mathrm{~N}$ NMR spectroscopy. ${ }^{26,42,45-49}$ Furthermore, ${ }^{13} \mathrm{C}$ magic angle spinning (MAS) NMR offers a sensitive probe for the phase purity of single and mixed cation perovskites. ${ }^{48}{ }^{2} \mathrm{H}$ and ${ }^{14} \mathrm{~N}$ NMR experiments are especially useful to study cation dynamics, which have been evaluated for the parent MA lead halide perovskite compounds ${ }^{45-47,49,50}$ and MA/FA and MA/ guanidinum mixed systems. ${ }^{26,39}$ Often NMR spectroscopic studies are complemented with first-principles simulations to obtain even more detailed information about the investigated material structure. ${ }^{51-53}$ However, the description of disordered systems requires a large set of models and large supercells rendering it computationally expensive, ${ }^{54-56}$ which is aggravated if dynamics play an important role and need to be modeled in addition, such as in halide perovskites. Recent developments in machine-learning force-fields (MLFFs) opened up the possibility of achieving near first-principles accuracy molecular dynamics (MD) trajectories of thousands of atoms on a nanosecond time scale. ${ }^{57}$ This allows for capturing cation dynamics and gaining detailed information about the microstructure in perovskites by $\mathrm{MD}$ simulation approaches. These MLFF MDs are able to resolve the entropydriven phase transitions in $\mathrm{MAPbI}_{3}$ and other related (inorganic) perovskites with great accuracy. ${ }^{57,58}$

In this work, we investigate the perovskite microstructure in detail, i.e., distribution and order/disorder of FA and MA in mixed halide perovskites of the form of $\mathrm{MA}_{1-x} \mathrm{FA}_{x} \mathrm{PbI}_{3}$ and $\mathrm{MA}_{0.15} \mathrm{FA}_{0.85} \mathrm{PbI}_{2.55} \mathrm{Br}_{0.45}$. High-resolution ${ }^{1} \mathrm{H}$ MAS NMR spectroscopy based on double-quantum (DQ) coherences allows us to identify individual ${ }^{1} \mathrm{H}-{ }^{1} \mathrm{H}$ correlations ${ }^{55,59-61}$ of MA and FA cations in close proximity and to quantify the ${ }^{1} \mathrm{H}$ dipolar interactions. Through a combination of the DQNMR data with MLFF MD simulations of the disordered and highly dynamic $\mathrm{MA}_{1-x} \mathrm{FA}_{x} \mathrm{PbI}_{3}$ systems, we are able to identify and quantify the effects that influence the experimentally determined ${ }^{1} \mathrm{H}-{ }^{1} \mathrm{H}$ dipolar couplings. Here, we also find that the latter significantly increases upon $\mathrm{Br}^{-}$incorporation in the perovskite structure. The knowledge about the nature of the dipolar couplings enables us to quantitatively analyze the relative occurrence of contacts between different cations in the 2D ${ }^{1} \mathrm{H}-{ }^{1} \mathrm{H}$ DQSQ MAS NMR spectra. This analysis indicates the presence of local compositional fluctuations due to a partial clustering of MA and FA cations over the entire investigated compositional range.
- EXPERIMENTAL AND COMPUTATIONAL METHODS

Synthesis. We synthesized the powders employing a mechanochemical approach ${ }^{62}$ by ball-milling in a Fritsch "Pulverisette 5/4" planetary ball mill. The reactants (FAI, MAI, $\mathrm{MABr}, \mathrm{PbI}_{2}$, and $\mathrm{PbBr}_{2}$ or already completely synthesized hybrid perovskites) were weighed to the desired stoichiometry (see Supporting Information for exact amounts) and transferred into an $80 \mathrm{~mL}$ stabilized $\mathrm{ZrO}_{2}$ milling jar, containing stabilized $\mathrm{ZrO}_{2}$ milling balls with $10 \mathrm{~mm}$ diameter. Then, 7$11 \mathrm{ml}$ of cyclohexane was added as a milling agent. The powders were milled at $400 \mathrm{rpm}$ for $5 \mathrm{~min}$. Then milling was paused for $20 \mathrm{~min}$ to allow cooling of the jar. The procedure was repeated until the desired milling time was reached. The cyclohexane was evaporated by opening the finished milling jar and leaving it at room temperature in air for $15 \mathrm{~min}$. Finally, we sieved the powder with a $90 \mu \mathrm{m}$ sieve. The resulting powders were transferred into an inert atmosphere for storage. FAI, MAI, and MABr were synthesized as described in ref 62, while $\mathrm{PbI}_{2}$ (purity >99.8\%) and $\mathrm{PbBr}_{2}$ (purity >98\%) were purchased from Sigma-Aldrich.

X-ray Diffraction. For powder diffraction analysis, samples were prepared inside a glovebox by hermetically sealing the powder in a $0.5 \mathrm{~mm}$ soda lime glass capillary. The X-ray diffractograms were recorded in capillary mode on a Panalytical Empyrean diffractometer using $\mathrm{Cu} \mathrm{K} \alpha$ radiation and a PIXcel3D $1 \times 1$ detector.

Solid-State NMR Spectroscopy. NMR spectra were recorded on Varian VNMRS systems operating at a magnetic field strength of $9.4 \mathrm{~T}(400 \mathrm{MHz})$ and $20.0 \mathrm{~T}(850 \mathrm{MHz})$. Probe heads used were a Varian $3.2 \mathrm{~mm}$ T3 HXY $(400 \mathrm{MHz})$ and a Varian $1.6 \mathrm{~mm} \mathrm{T3} \mathrm{HXY}(850 \mathrm{MHz})$ probe. The chemical shift was referenced using lead nitrate for ${ }^{207} \mathrm{~Pb}$ $(-3494 \mathrm{ppm})$ and using adamantane for ${ }^{1} \mathrm{H}(1.85 \mathrm{ppm})$ and ${ }^{13} \mathrm{C}(38.5 \mathrm{ppm})$ as secondary references. All experiments were performed at room temperature and using boil-off nitrogen for performing MAS.

${ }^{207} \mathrm{~Pb}$ MAS NMR spectra were recorded at $5 \mathrm{kHz}$ spinning speed with a recycle delay of $0.5 \mathrm{~s}$.

Single-pulse excitation (SPE) ${ }^{13} \mathrm{C}$ MAS NMR spectra were recorded at $12.5 \mathrm{kHz}$ MAS rate, with a recycle delay of 75-90 $\mathrm{s}$ to ensure full relaxation $\left({ }^{13} \mathrm{C} T_{1} \sim 15 \mathrm{~s}\right)$ and thus warrant quantitative results. SPINAL ${ }^{63}$ decoupling at an ${ }^{1} \mathrm{H}$ decoupling strength of $50 \mathrm{kHz}$ was employed during acquisition.

For ${ }^{1} \mathrm{H}-{ }^{13} \mathrm{C}$ CP-MAS spectra, rf field strengths were optimized using adamantane $\left(\nu\left({ }^{1} \mathrm{H}\right) \sim 60 \mathrm{kHz}\right.$ and $\nu\left({ }^{13} \mathrm{C}\right)$ $\sim 72 \mathrm{kHz}$ ). CP contact times were optimized for each sample resulting in values of $15-50 \mathrm{~ms}$. For such long pulses it is important to carefully obey the power limits of the hardware. Proton decoupling (SPINAL) was employed at a field strength of $50 \mathrm{kHz}$, the recycle delay was set to $50-70 \mathrm{~s}\left({ }^{1} \mathrm{H} T_{1} \sim 10-\right.$ $14 \mathrm{~s}$ determined by ${ }^{1} \mathrm{H}$ saturation recovery experiments), and an MAS frequency of $12.5 \mathrm{kHz}$ was used.

High-resolution ${ }^{1} \mathrm{H}$ MAS NMR experiments were performed at a magnetic field of $850 \mathrm{MHz}$ and a MAS frequency of 35 $\mathrm{kHz}$. For $1 \mathrm{D}{ }^{1} \mathrm{H}$ MAS NMR spectra the recycle delays (65$120 \mathrm{~s}$ ) were optimized for each sample to reach full relaxation $\left({ }^{1} \mathrm{H} T_{1} \sim 13-24 \mathrm{~s}\right.$ determined by ${ }^{1} \mathrm{H}$ saturation recovery experiments). 2D ${ }^{1} \mathrm{H}-{ }^{1} \mathrm{H}$ DQSQ MAS NMR spectra and ${ }^{1} \mathrm{H}$ DQ buildup curves were recorded using the BABA-xy $16^{64}$ sequence $\left(\nu\left({ }^{1} \mathrm{H}\right) \sim 140 \mathrm{kHz}\right)$ at a MAS rate of $35 \mathrm{kHz}$. Zero- 
a) XRD

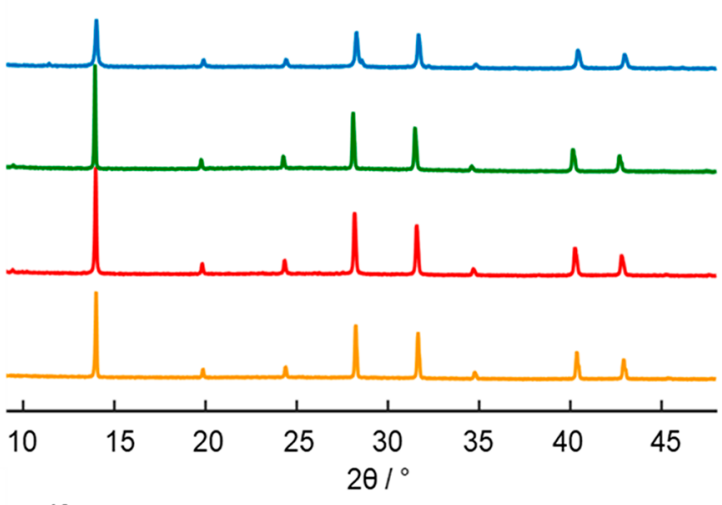

c) ${ }^{13} \mathrm{C}$ CPMAS

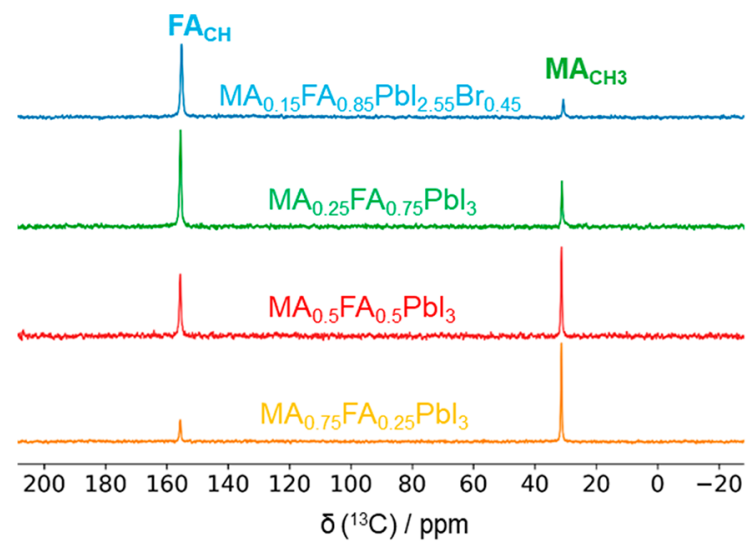

b) ${ }^{207} \mathrm{~Pb}$ MAS

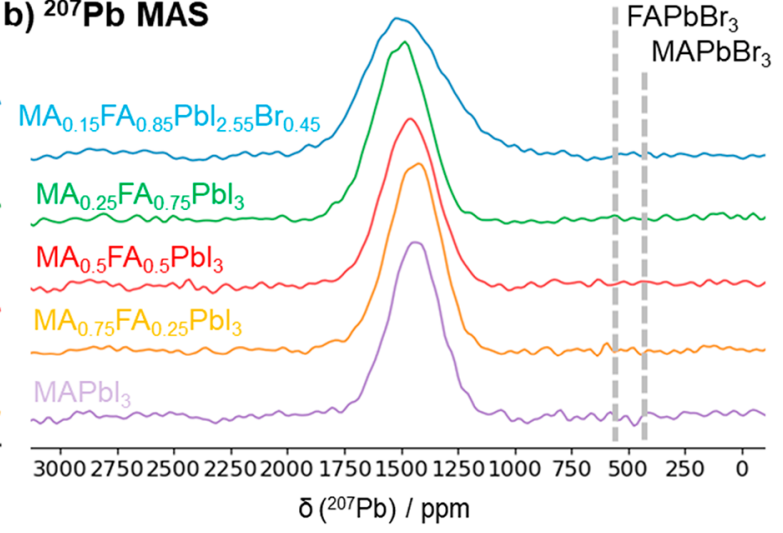

d) ${ }^{1} \mathrm{H}$ MAS

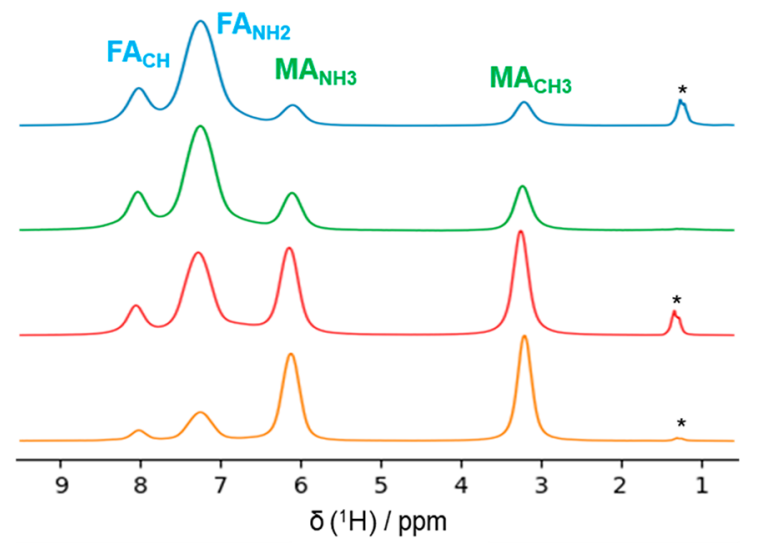

Figure 1. (a) XRD patterns, (b) ${ }^{207} \mathrm{~Pb}$ MAS NMR spectra, (c) ${ }^{1} \mathrm{H}-{ }^{13} \mathrm{C}$ CP-MAS NMR, and (d) ${ }^{1} \mathrm{H}$ MAS NMR spectra of the three mixed $\mathrm{MA}_{1-x} \mathrm{FA}_{x} \mathrm{PbI}_{3}$ samples $\left(x=0.25\right.$, orange; $x=0.5$, red; $x=0.75$, green), as well as of the double-mixed sample $\mathrm{MA}_{0.15} \mathrm{FA}_{0.85} \mathrm{PbI}_{2.55} \mathrm{Br}_{0.45}(\mathrm{blue})$. (a) The XRD patterns of all samples show reflections of a cubic crystal lattice. The lattice constants are summarized in Table S1. (b) Additionally, a ${ }^{207} \mathrm{~Pb}$ MAS NMR spectrum of $\mathrm{MAPbI}_{3}\left(\delta_{\text {iso }}=1430 \mathrm{ppm}\right)$ is depicted for comparison and dashed lines indicate chemical shifts for $\mathrm{FAPbBr}_{3}$ and $\mathrm{MAPbBr}_{3}$ from literature. ${ }^{50,76,77} \mathrm{The}^{207} \mathrm{~Pb}$ isotropic chemical shift of $\alpha$-FAPbI ${ }_{3}$ is reported to be $1495 \mathrm{ppm} .{ }^{77}$ (d) Asterisks in the ${ }^{1} \mathrm{H}$ MAS NMR spectra indicate a small cyclohexane impurity, which is also observed in the ${ }^{13} \mathrm{C}$ SPE MAS NMR spectra (Figure S2).

quantum (ZQ) reference measurements were used for a normalization of the ${ }^{1} \mathrm{H}$ DQ buildup curves: ${ }^{60,64}$

$$
\text { DQ efficiency: } \quad I_{\mathrm{DQ}}^{\text {norm }}\left(t_{\mathrm{exc}}\right)=\frac{I_{\mathrm{DQ}}\left(t_{\text {exc }}\right)}{I_{\mathrm{ZQ}}\left(t_{\mathrm{exc}}\right)+I_{\mathrm{DQ}}\left(t_{\mathrm{exc}}\right)}
$$

Molecular Dynamics with Machine-Learning Force Fields. A smoothened machine-learned potential energy surface is modeled by the Gaussian approximation potential ${ }^{65}$ with two- and three-body descriptors and kernel function similar to the smooth overlap atomic positions (SOAP) method. ${ }^{66}$ The descriptors are defined within a cutoff sphere of 6 or $4 \AA$ for the two or three body term, respectively. They are discretized on radial basis functions $\left(N_{R}=6\right.$ or 7$)$ and, for the three body term, multiplied with spherical harmonics $\left(l_{\max }=\right.$ 4). The reference structures to train the MLFF are selected onthe-fly during first-principles molecular dynamics calculations under isothermal-isobaric conditions; see refs 57 and 67 for methodological details. This method is integrated in the Vienna ab initio simulation package (VASP) $\operatorname{code}^{68,69}$ and calculates the potential energy, forces on the atoms, and stress tensor for all the reference structures, which are, by construction, well spread over the available structural phase space. The state-of-the-art meta-gradient corrected functional $\mathrm{SCAN}^{70}$ is applied in the first-principles (FP) calculations, since it accurately describes the physical interactions in the material. ${ }^{71}$ The electronic minimization was performed within the projector augmented wave formalism ${ }^{72}$ with a plane wave basis (cutoff $350 \mathrm{eV}$ ), a $2 \times 2 \times 2$ k-point grid, and Gaussian smearing $(\sigma=0.01 \mathrm{eV})$. For the training, three $2 \times 2 \times 2$ unit cells of $\mathrm{MA}_{1-x} \mathrm{FA}_{x} \mathrm{PbI}_{3}(x=0,0.5,1)$ each containing eight cations were used. Starting from scratch, we trained the MLFF on $\mathrm{FAPbI}_{3}(x=1)$ for $100 \mathrm{ps}$ at $400 \mathrm{~K}$ with time steps of $3 \mathrm{fs}$, resulting in 707 included reference structures. Hereafter, training was continued on $\mathrm{MAPbI}_{3}(x=0)$ for the same time and at the same temperature. The total number of reference structures in the resulting MLFF was only raised to 836. Last, we trained in the same way on $\mathrm{MA}_{0.5} \mathrm{FA}_{0.5} \mathrm{PbI}_{3}$; this increased the number to a total of 960 structures. These structures supply the finished MLFF with 121, 1432, 201, 244, and 1213 local reference configurations for the $\mathrm{Pb}, \mathrm{I}, \mathrm{C}, \mathrm{N}$, and $\mathrm{H}$ atoms, respectively. This MLFF was then used (in production mode, i.e., no more training) for all $\mathrm{MD}$ simulations shown in this work.

For the MLFF isothermal and isobaric NPT-MD simulations $4 \times 4 \times 4$ unit cells of $\mathrm{MA}_{1-x} \mathrm{FA}_{x} \mathrm{PbI}_{3}$ were constructed with $x$ $=0,1 / 8,1 / 4, \ldots, 1$, where Langevin thermo- and barostats were applied to control the conditions. To study the influence of the spatial distribution of the FA and MA cations, ordered $(\mathrm{O})$ and randomly $(\mathrm{R})$ packed cells were constructed. In the $\mathrm{O}$ case, the $4 \times 4 \times 4$ cells are constructed by replicating $2 \times 2 \times 2$ unit cells in which the cations are distributed to maximize the 

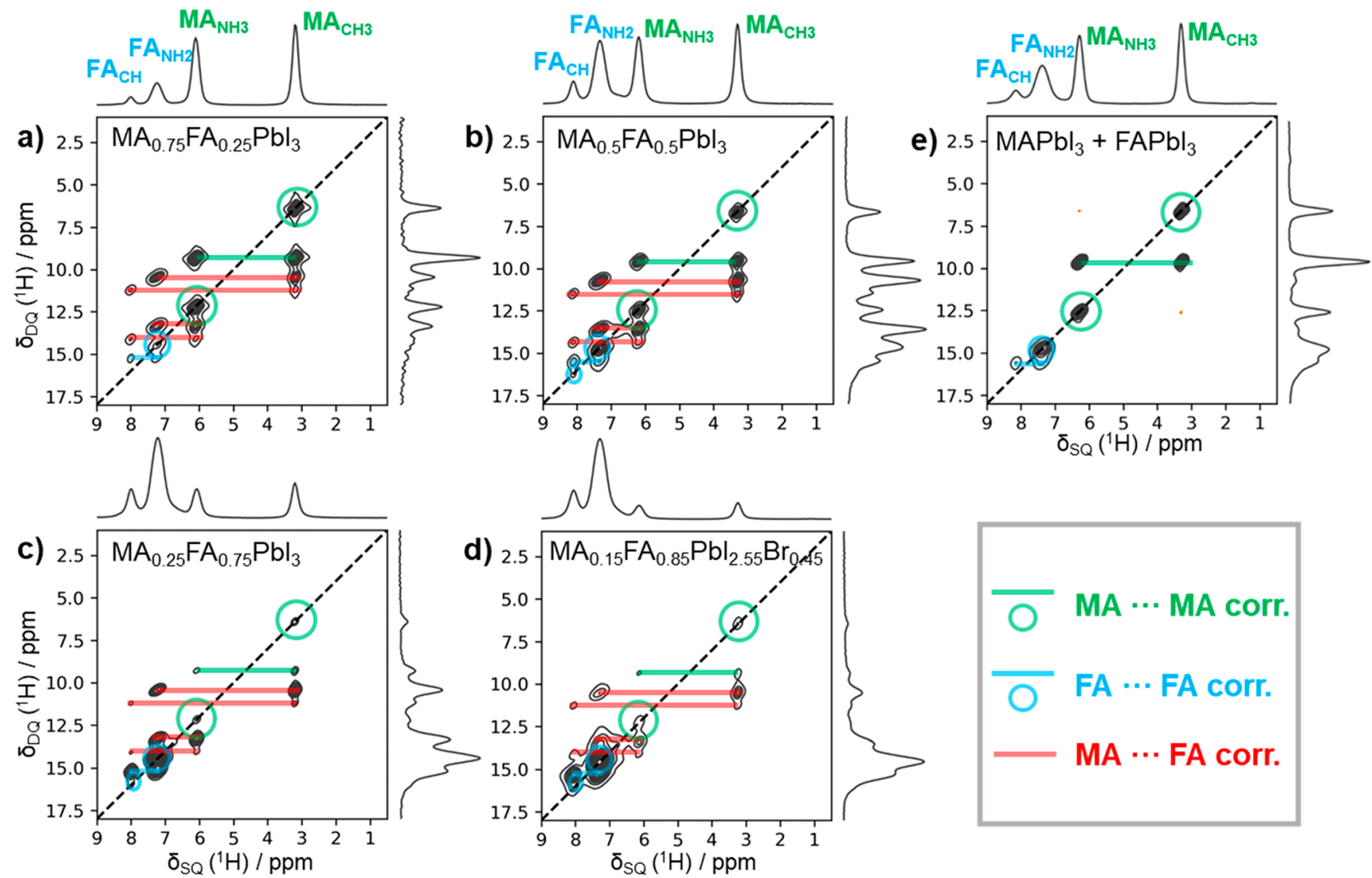

Figure 2. 2D ${ }^{1} \mathrm{H}-{ }^{1} \mathrm{H}$ DQSQ MAS NMR spectra of the mixed perovskite samples (a-d), as well as of a physical mixture of $\mathrm{MAPbI}_{3}$ and $\alpha$-FAPbI ${ }_{3}$ (e) at an excitation time $t_{\text {exc }}$ of $229 \mu$ s. Solid lines between resonances and circles on diagonal signals mark ${ }^{1} \mathrm{H}-{ }^{1} \mathrm{H}$ correlations between $\mathrm{MA}$ cations (green), FA cations (blue), and MA-FA cations (red). The existence of mixed MA-FA correlations demonstrates a successful mixing of $\mathrm{MA}$ and FA on the A site for all mixed perovskite compositions $(\mathrm{a}-\mathrm{d})$, while in the case of cation phase segregation the red correlations would diminish as in the case of a physical mixture $\mathrm{MAPbI}_{3}$ and $\alpha-\mathrm{FAPbI}_{3}$ (e).

distance to neighboring cations of the same species. In the $\mathrm{R}$ cells, the cations are randomly placed. All $4 \times 4 \times 4$ cells were run for $100 \mathrm{ps}$ at 300 and $400 \mathrm{~K}$ under 1 bar standard pressure. We calculate the dipolar coupling coefficient between all $\mathrm{H}-\mathrm{H}$ pairs and divide them in two groups, with the intra- and intermolecular $\mathrm{H}-\mathrm{H}$ connecting vectors. Applying the ensemble averaging over time and space following the approach by Goc et al. ${ }^{73-75}$ (see Supporting Information for details) then gives the average dipolar coupling that can be compared to the value measured by NMR.

\section{RESULTS AND DISCUSSION}

Characterization. We prepared three mixed cation perovskites of the form $\mathrm{MA}_{1-x} \mathrm{FA}_{x} \mathrm{PbI}_{3}$ with $x=0.25,0.50,0.75$ and a mixed cation and mixed halide composition $\mathrm{MA}_{0.15} \mathrm{FA}_{0.85} \mathrm{PbI}_{2.55} \mathrm{Br}_{0.45}$ (here referred to as double-mixed) by mechanochemical synthesis. The resulting powders were analyzed by powder X-ray diffraction, ${ }^{207} \mathrm{~Pb} \mathrm{MAS}$, as well as ${ }^{13} \mathrm{C}$ MAS and high-resolution ${ }^{1} \mathrm{H}$ MAS NMR spectroscopy to determine their crystal structure, exact FA/MA ratio, and possible impurities. The XRD patterns of all samples (Figure 1a) show reflections of a cubic lattice corroborating the stabilization of the cubic lattice upon mixing FA and MA cations. $^{26-28}$ The corresponding lattice constants (Table S1) for $\mathrm{MA}_{1-x} \mathrm{FA}_{x} \mathrm{PbI}_{3}$ increase from 6.31 to $6.34 \AA$ with increasing FA content, while the double-mix shows a smaller lattice constant of $6.30 \AA$ due to incorporation of the smaller $\mathrm{Br}^{-}$ion, consistent with literature observations. ${ }^{34}$ All ${ }^{207} \mathrm{~Pb}$ MAS NMR spectra of the mixed samples and $\mathrm{MAPbI}_{3}$ (Figure 1b) show a single resonance, which gradually shifts with increasing FA content from $1430 \mathrm{ppm}$ for $\mathrm{MAPbI}_{3}$ to $1490 \mathrm{ppm}$ for $\alpha$ FAPbI $_{3}{ }^{50,76,77}$ The ${ }^{207} \mathrm{~Pb}$ MAS NMR spectrum of the doublemixed sample $\mathrm{MA}_{0.15} \mathrm{FA}_{0.85} \mathrm{PbI}_{2.55} \mathrm{Br}_{0.45}$ (Figure 1b, blue) reveals a broadening of the ${ }^{207} \mathrm{~Pb}$ resonance in comparison to the other mixed cation perovskites. In general, multiple effects can play a role in the ${ }^{207} \mathrm{~Pb}$ line shape: $T_{2}$ broadening due to very short spin-spin relaxation, scalar couplings between $\mathrm{Pb}-\mathrm{X}$ species, or disorder around the lead atoms by halide mixing. ${ }^{49,76-79}$ Scalar couplings were found prominent for $\mathrm{CsPb}_{3}$, while for MA- and FA-based perovskites only $\mathrm{Pb}-\mathrm{Cl}$ species show features arising from the $J$-couplings but not for $\mathrm{Pb}-\mathrm{I}$ or $\mathrm{Pb}-\mathrm{Br}$ species at room temperature. $^{78}$ Therefore, as the observed broadening is slightly asymmetric and the spin-spin relaxation $\left(T_{2}\right.$ relaxation) of pure $\mathrm{MAPbI}_{3}$ at room temperature is already very short $(\sim 40 \mu \mathrm{s}),{ }^{49}$ we attribute the observed additional broadening for $\mathrm{MA}_{0.15} \mathrm{FA}_{0.85} \mathrm{PbI}_{2.55} \mathrm{Br}_{0.45}$ to $\mathrm{I} / \mathrm{Br}$ mixing. This, in combination with the absence of any signal intensity in the chemical shift region for $\mathrm{MAPbBr}_{3}$ and $\mathrm{FAPbBr}_{3}$ (300-600 $\mathrm{ppm}),{ }^{50,76,77,79}$ corroborates the incorporation of the $\mathrm{Br}^{-}$ions in the lattice.

Characterization of the cations in terms of types and ratios, as well as the identification of impurities, is achieved by recording single-pulse ${ }^{13} \mathrm{C}$ MAS (Figure S1) and ${ }^{1} \mathrm{H}-{ }^{13} \mathrm{C}$ 
cross-polarization (CP) MAS NMR spectra (Figure 1c), which show the typical resonances at $155.5 \mathrm{ppm}$ for the $\mathrm{CH}$-group of $\mathrm{FA}$ and at $31.3 \mathrm{ppm}$ for the $\mathrm{CH}_{3}$-group of the MA cation. Additionally, the direct ${ }^{13} \mathrm{C}$ single-pulse excitation (SPE) NMR spectra of $\mathrm{MA}_{0.15} \mathrm{FA}_{0.85} \mathrm{PbI}_{2.55} \mathrm{Br}_{0.45}$ and $\mathrm{MA}_{0.5} \mathrm{FA}_{0.5} \mathrm{PbI}_{3}$ (Figure S1) exhibit a sharp resonance at $27.5 \mathrm{ppm}$, which is absent in the CPMAS NMR spectra, suggesting that the heteronuclear dipolar coupling between ${ }^{1} \mathrm{H}$ and ${ }^{13} \mathrm{C}$ is averaged, indicative of a small, mobile impurity. The high-resolution ${ }^{1} \mathrm{H}$ MAS NMR spectra of all samples (Figure 1d) show four distinct signals, which can readily be assigned to the ${ }^{1} \mathrm{H}$ species of the MA and FA cations. The signals of the $\mathrm{CH}_{3}$-group and the $\mathrm{NH}_{3}$-group of the MA cation occur at chemical shifts of 3.3 and $6.2 \mathrm{ppm}$, respectively, while the $\mathrm{NH}_{2}$-groups and the $\mathrm{CH}$-group of the FA cation are observed at 7.3 and $8.1 \mathrm{ppm}$. For $\mathrm{MA}_{0.15} \mathrm{FA}_{0.85} \mathrm{PbI}_{2.55} \mathrm{Br}_{0.45}, \quad \mathrm{MA}_{0.5} \mathrm{FA}_{0.5} \mathrm{PbI}_{3}$, and $\mathrm{MA}_{0.75} \mathrm{FA}_{0.25} \mathrm{PbI}_{3}$ an additional sharp signal is observed at 1.4 ppm, which together with the ${ }^{13} \mathrm{C}$ NMR signal at $27.5 \mathrm{ppm}$ is assigned to residual cyclohexane, which was used as a milling agent in the mechanochemical synthesis of the powders. The cation ratios obtained from the ${ }^{13} \mathrm{C}$ and ${ }^{1} \mathrm{H}$ NMR spectra are in excellent agreement with the nominal ratios from the synthesis as summarized in Table S2.

Intermolecular Cation Interactions. In order to probe the distribution and mixing behavior of MA and FA cations in the different mixed perovskite systems, we recorded twodimensional (2D) ${ }^{1} \mathrm{H}-{ }^{1} \mathrm{H}$ DQSQ MAS NMR spectra. ${ }^{1} \mathrm{H}-{ }^{1} \mathrm{H}$ correlations of protons in close proximity with similar chemical environments result in signals along the diagonal $\left(\delta_{\mathrm{DQ}}=2 \delta_{\mathrm{SQ}}\right)$ of the $2 \mathrm{D}$ spectra, while off-diagonal resonances stem from correlations between protons of differing chemical groups at the sum of the corresponding chemical shifts $\left(\delta_{\mathrm{DQ}}=\delta_{\mathrm{SQ} 1}+\right.$ $\left.\delta_{\mathrm{SQ} 2}\right)$.

The experimental 2D ${ }^{1} \mathrm{H}-{ }^{1} \mathrm{H}$ DQSQ MAS NMR spectra of the four mixed samples are shown in Figure $2 a-d$. We observe correlations between the ${ }^{1} \mathrm{H}$ resonances of MA cations (MAMA; green; $\delta_{\mathrm{DQ}}=6.6,9.5$, and $12.4 \mathrm{ppm}$ ), between the ${ }^{1} \mathrm{H}$ resonances of FA cations (FA-FA; blue; $\delta_{\mathrm{DQ}}=14.7,15.5$, and $16.2 \mathrm{ppm})$, and between the ${ }^{1} \mathrm{H}$ resonances of $\mathrm{MA}$ and $\mathrm{FA}$ cations (MA-FA; red; $\delta_{\mathrm{DQ}}=10.7,11.5,13.6$, and $14.4 \mathrm{ppm}$ ). The occurrence of MA-MA, FA-FA, and MA-FA correlations indicates the mixing of the cations for all compositions. In contrast, a $2 \mathrm{D}{ }^{1} \mathrm{H}-{ }^{1} \mathrm{H}$ DQSQ MAS NMR spectrum for a physical mixture of $\alpha-\mathrm{FAPbI}_{3}$ and $\mathrm{MAPbI}_{3}$ (Figure 2e) only shows DQ correlations between MA cations (green), as well as FA cations (blue), but no FA-MA correlations, as expected for a phase-separated system.

After qualitatively determining the ${ }^{1} \mathrm{H}-{ }^{1} \mathrm{H}$ correlations from the $2 \mathrm{D}{ }^{1} \mathrm{H}-{ }^{1} \mathrm{H}$ DQSQ MAS NMR spectra, a quantification of the interaction strength between the coupled ${ }^{1} \mathrm{H}$ species of the FA and MA cations provides further structural information. These can be accessed as the dipolar coupling is proportional to the number of contributing spins, as well as their relative alignment and distance (eq 4). ${ }^{55,60,80,81}$ Therefore, $1 \mathrm{D}{ }^{1} \mathrm{H}$ DQ buildup curves, which describe the buildup of DQ intensities of coupled spins as a function of excitation time, were recorded for all mixed perovskite samples, as well as the physical mixture of $\mathrm{MAPbI}_{3}$ and $\alpha$-FAPbI ${ }_{3}$ (Figure S3). In the latter case, the DQ buildup curves are distinguishable for MA and FA signals (Figures $3 \mathrm{a}$ and $\mathrm{S} 3$ ). In contrast, for the mixed $\mathrm{MA}_{1-x} \mathrm{FA}_{x} \mathrm{PbI}_{3}$ and the double-mixed $\mathrm{MA}_{0.15} \mathrm{FA}_{0.85} \mathrm{PbI}_{2.55} \mathrm{Br}_{0.45}$, the individual DQ buildup curves for each ${ }^{1} \mathrm{H}$ signal corresponding to $\mathrm{MA}_{\mathrm{CH} 3}, \mathrm{MA}_{\mathrm{NH} 3}, \mathrm{FA}_{\mathrm{NH} 2}$, and $\mathrm{FA}_{\mathrm{CH}}$ show a very similar behavior
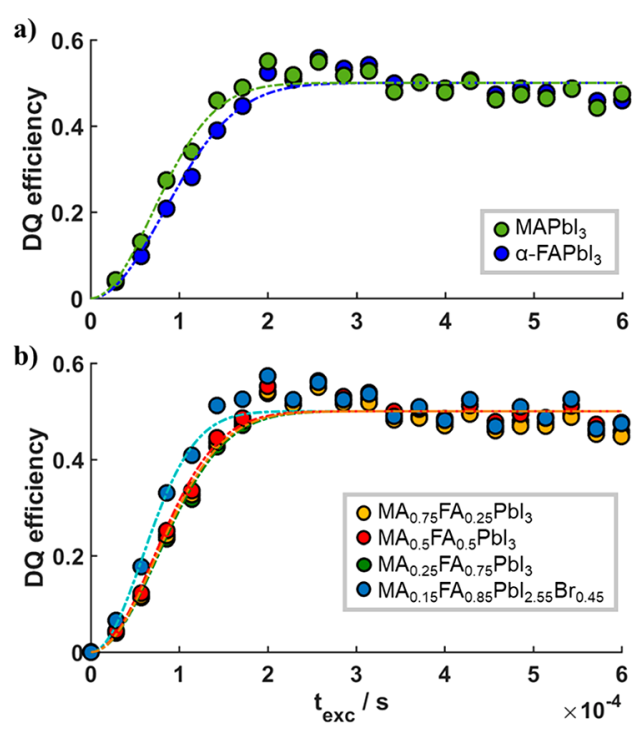

Figure 3. Average ${ }^{1} \mathrm{H}$ DQ buildup curves (a) of $\mathrm{MAPbI}_{3}$ (green) and $\alpha$ - $\mathrm{FAPbI}_{3}$ (blue) and (b) of the mixed perovskite compositions $\mathrm{MA}_{1-x} \mathrm{FA}_{x} \mathrm{PbI}_{3}$ (yellow, red, green), as well as $\mathrm{MA}_{0.15} \mathrm{FA}_{0.85} \mathrm{PbI}_{2.55} \mathrm{Br}_{0.45}$ (blue). The dashed lines are fits of the DQ buildup curves according to eq 2 to extract the average dipolar couplings, which are summarized in Figure 5 and Table S3.

(Figure S3). Therefore, for each mixed composition, it is reasonable to average the individual DQ buildup curves resulting in the average DQ buildup curves shown in Figure $3 \mathrm{~b}$. All experimental DQ buildup curves exhibit the typical shape of a multispin system (Figure S3) with a distribution of dipolar interactions, which can be analyzed using either expensive modeling ${ }^{55}$ or a second moment approximation. ${ }^{60,64}$ Here, we used the so-called BABA-xy16 pulse sequence, which can be evaluated by the following approach to extract the average dipolar couplings: ${ }^{64}$

$$
\begin{aligned}
& \text { DQ efficiency: } \quad I_{\mathrm{DQ}}^{\mathrm{norm}} \approx\left\langle\sin ^{2} \phi\right\rangle \approx \frac{1}{2}\left\{1-\mathrm{e}^{-2\left\langle\phi^{2}\right\rangle}\right\} \\
& \left\langle\phi^{2}\right\rangle=\frac{6}{5 \pi^{2}} \bar{D}^{2} t_{\mathrm{exc}}{ }^{2}
\end{aligned}
$$

The average dipolar coupling $\bar{D}$ in this approach is defined as ${ }^{60}$

$$
\bar{D}^{2}=\sum_{i, j}\left(\frac{\mu_{0} \hbar \gamma_{i} \gamma_{j}}{4 \pi r_{i j}{ }^{3}}\right)^{2}
$$

The extracted average dipolar couplings $\bar{D}$ from the experimental data for the mixed compositions show a gradual increase with increasing MA content, from about $2800 \mathrm{~Hz}$ for pure $\alpha-\mathrm{FAPbI}_{3}$ to $\sim 3300 \mathrm{~Hz}$ for $\mathrm{MAPbI}_{3}$ (Figure 5, pink, Table S3). In contrast, the double-mixed composition $\mathrm{MA}_{0.15} \mathrm{FA}_{0.85} \mathrm{PbI}_{2.55} \mathrm{Br}_{0.45}$ exhibits a significantly larger dipolar coupling of $\sim 3900 \mathrm{~Hz}$ (Figure 5, light blue, Table S3). It is expected that the fast reorientation of the MA and FA cations within their cage in the perovskite lattice ${ }^{26,43,47}$ will average the intramolecular dipolar interaction within the cations. Thus, the extracted dipolar couplings are connected to the number of FA and MA cations contributing, as FA has five and MA has six hydrogen atoms, and the average spatial intermolecular distances between neighboring cations. The decrease in $\bar{D}$ with increasing FA content $x$ could be related to a smaller number of contributing protons or to, on average, longer 
distances between hydrogens in nearest neighbor cations or a combination thereof.

In order to understand the correlation between the dipolar coupling $\bar{D}$ and the FA content $x$ (Figure 5), we carry out state-of-the-art MLFF molecular dynamics simulations of $\mathrm{MA}_{1-x} \mathrm{FA}_{x} \mathrm{PbI}_{3}$ supercells containing a total of $64 \mathrm{MA}$ and/ or FA cations with long simulation times (100 ps). The MD trajectories are used to calculate the $\mathrm{H}-\mathrm{H}$ pair distribution function $g(r)$ (eq 5, Figure S4) that describes the likelihood to find $\mathrm{H}$ atoms at distances $r$ :

$$
g(r)=\frac{V}{4 \pi r^{2} N^{2}}\left\langle\sum_{i} \sum_{j \neq i} \delta\left(r-r_{i j}\right)\right\rangle
$$

Figure $4 \mathrm{a}$ depicts the pair distribution function for nearest neighbor coordinations (2-5 $)$ for $\mathrm{MAPbI}_{3}, \mathrm{MA}_{0.5} \mathrm{FA}_{0.5} \mathrm{PbI}_{3}$,
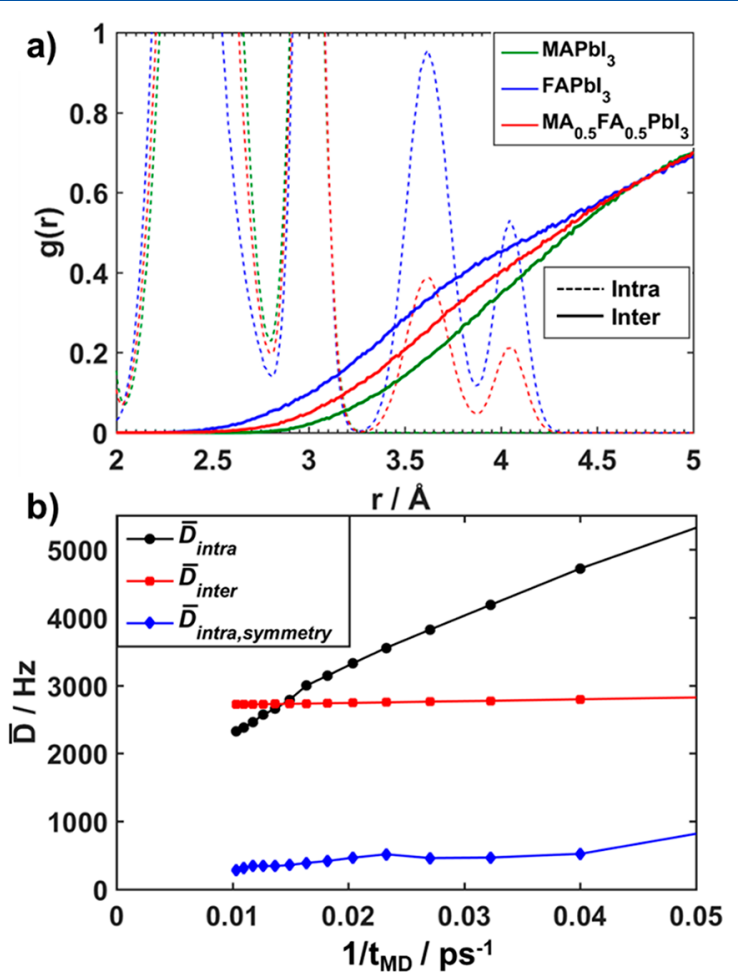

Figure 4. (a) Close-up of the pair distribution function between 2 and $5 \AA$ for hydrogen atoms in $\mathrm{MA}_{1-x} \mathrm{FA}_{x} \mathrm{PbI}_{3}$ for $x=0,0.5$, and 1 obtained in the cubic phase at $400 \mathrm{~K}$. The intra- and intermolecular contributions are depicted separately to demonstrate the onset of the intermolecular contributions. The full $\mathrm{H}-\mathrm{H}$ pair distribution function of the simulation is depicted in the Supporting Information (Figure S4). (b) Intra- (black) and intermolecular (red) contributions to the average dipolar coupling as a function of simulation time for $\mathrm{MA}_{0.5} \mathrm{FA}_{0.5} \mathrm{PbI}_{3}$. Additionally, the intramolecular term averaged by applying symmetry of the intramolecular $\mathrm{H}-\mathrm{H}$ vectors is shown in blue.

and $\alpha-\mathrm{FAPbI}_{3}$ (see Figure S4 for full range). The distances resulting from intramolecular $\mathrm{H}-\mathrm{H}$ pairs are between 1.5 and $4.5 \AA$ depending on the molecular structure of the cations FA and MA (Figure S4). The onset of the intermolecular part of $g(r)$ occurs at larger distances for MA cations $(x=0)$ than for FA cations $(x=1)$, and it gradually decreases with increasing $x$ (Figure 4a), as expected considering the different MA and FA cation sizes. ${ }^{2}$ As observed above, an opposite trend is needed to explain the decrease of $\bar{D}$ with increasing $x$ considering only interatomic distances. Evidently, an interpretation of the dipolar couplings in terms of average intermolecular distances between the cations is insufficient.

To clarify these apparently contradicting results, we calculate the average dipolar coupling $(\bar{D})$ directly from the MD trajectories following the approach of Goc et al. ${ }^{73-75}$ (Supporting Information, section 5). This provides access to the intra- and intermolecular contribution to $\bar{D}$ as a function of the inverse trajectory length $\left(1 / t_{\mathrm{MD}}\right)$. In Figure $4 \mathrm{~b}$ the black and red lines show the intra- and intermolecular contribution in $\mathrm{MA}_{0.5} \mathrm{FA}_{0.5} \mathrm{PbI}_{3}$, respectively. The intramolecular contribution decays only slowly with time, whereas the intermolecular contribution quickly converges and thus appears nearly constant (see Figure $4 \mathrm{~b}$ and Figure S5). About 100 ps (1/ $\left.t_{\mathrm{MD}}=0.01 \mathrm{ps}^{-1}\right)$ of simulation time is needed for the intramolecular contribution to be smaller than the intermolecular contribution. The intramolecular contribution is still noticeably decreasing after these 100 ps. In view of the nearly free rotation of the cations in the cubic perovskite lattice, on longer time scales $\left(1 / t_{\mathrm{MD}} \rightarrow 0 \mathrm{ps}^{-1}\right)$ one would expect a (vanishly) small intramolecular dipolar coupling. This can be demonstrated if costly MD runs are carried out for which several orders of magnitude longer simulation times will be needed. As an alternative, it is possible to significantly reduce the computational effort by considering symmetry within the large supercell (see Supporting Information). Averaging over similar intramolecular $\mathrm{H}-\mathrm{H}$ vectors results in three remaining inequivalent vectors for MA and six for FA. In this way we can improve the statistics for $\bar{D}_{\text {intra }}$ without elongating the trajectory, which causes a drastic reduction of $\bar{D}_{\text {intra }}$ (Figure $4 \mathrm{~b}$, blue, and Figure S5). These results demonstrate that the average dipolar coupling $\bar{D}$ is very well approximated by solely considering intermolecular contributions, i.e., $\bar{D}_{\text {intra }}=0$ on the NMR time scale.

In Figure 5 the calculated $\bar{D}$ versus perovskite composition $x$ is plotted as well as the experimental values obtained from the ${ }^{1} \mathrm{H}$ DQ buildup curves. The values calculated for the $\mathrm{MA}_{1-x} \mathrm{FA}_{x} \mathrm{PbI}_{3}$ systems are in excellent agreement with the experiment. The small offset $(\sim 300-400 \mathrm{~Hz})$ of the calculated values is caused by the slightly larger lattice constant $(\sim 0.08$ $\AA$ ) predicted by the MLFF (Figure S1). At $400 \mathrm{~K}$ simulation temperature the lattice constants are slightly larger $(\sim 0.02 \AA)$ than at $300 \mathrm{~K}$ due to thermal expansion (Figure S1), which results in a decrease of the calculated $\bar{D}$ (Figure 5). In order to investigate the influence of the packing order on the calculated $\bar{D}$ values, we also compared two types of homogeneous distributions of FA and MA cations, a random (R) and an ordered (O) packing. The $\mathrm{O}$ packing represents FA and MA cations in alternating positions resulting in solely nearestneighbor MA-FA correlations for $x=0.5$. Interestingly, we find that the packing order has no noticeable effect on the average dipolar interaction $\bar{D}$ between the cations (Figure S6).

With these results it becomes clear that the linear dependence of $\bar{D}$ on $x$ stems from a change of the contributing average amount of hydrogen pairs in the mixed perovskites. As MA possesses six hydrogens, whereas FA has only five, the average dipolar coupling $\bar{D}$ decreases with increasing FA content $x$ (Figure 5, pink and black solid). Placing all $\mathrm{H}$ in the center of the A lattice site is also a good approximate model (Figure 5, black lines). In contrast, the ordering of MA/FA on the grid and the change of the (pseudo)cubic lattice constant have a much smaller effect. As the change of $\bar{D}$ with $x$ is dominated by the hydrogen content in mixed $\mathrm{MA}_{1-x} \mathrm{FA}_{x} \mathrm{PbI}_{3}$, 


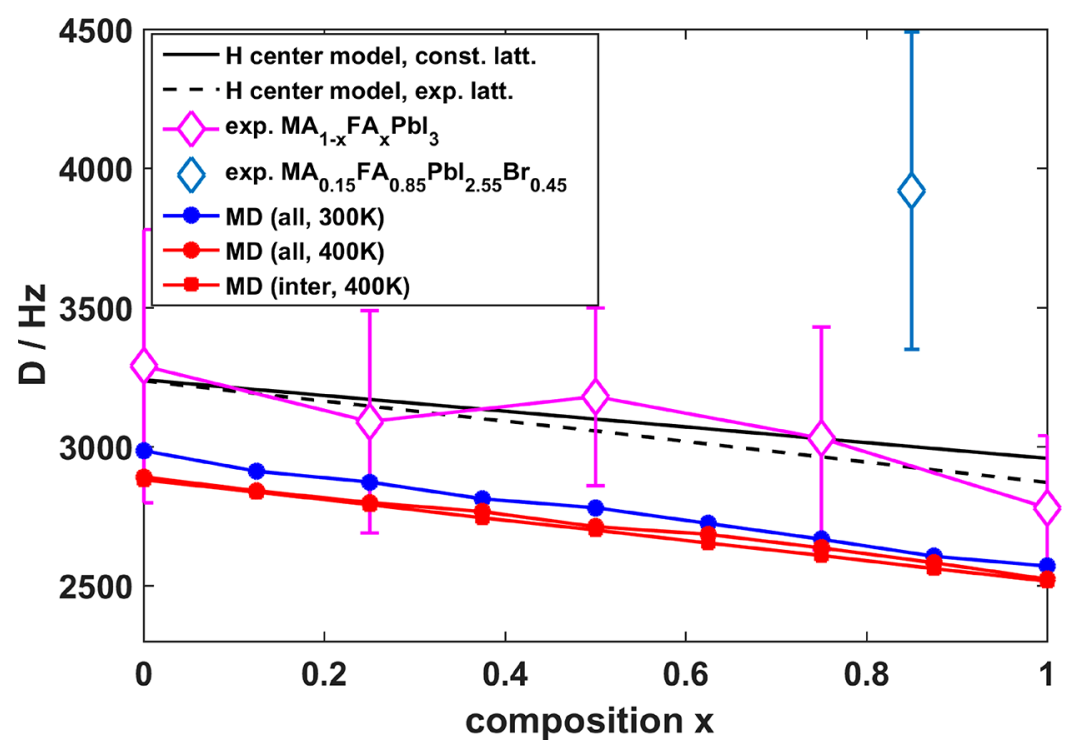

Figure 5. Average ${ }^{1} \mathrm{H}$ dipolar couplings for $\mathrm{MA}_{1-x} \mathrm{FA}_{x} \mathrm{PbI}_{3}$ extracted from ${ }^{1} \mathrm{H}$ DQ buildup curves (pink) and $\mathrm{MD}$ simulations at $300 \mathrm{~K}$ (blue) and $400 \mathrm{~K}$ (red, solid line). Additionally, solely intermolecular contributions to $\bar{D}$ are shown for the MD run at $400 \mathrm{~K}$ (red, dashed lines) revealing minor differences to the full average dipolar coupling (red, solid line). Additionally, linear trends resulting from models, where all $\mathrm{H}$ atoms are placed in the center of the lattice A site neglecting dynamics, etc., are depicted in black. The solid line depicts the model with a fixed lattice constant over the whole compositional space resulting in a linear curve with a slope proportional to the hydrogen ratio of FA and MA $\left(y=(\sqrt{ }(5 / 6)-1) D_{0}\right.$ $+D_{0}$, black solid). The dashed black line is the model using experimental lattice constants of $\mathrm{MA}_{1-x} \mathrm{FA}_{x} \mathrm{PbI}_{3}$, fitting the experimental data slightly better. This demonstrates that the linear dependence of $\bar{D}$ on $x$ is dominated by the number of contributing spins. Furthermore, the experimental average dipolar coupling of the double-mixed perovskite composition $\mathrm{MA}_{0.15} \mathrm{FA}_{0.85} \mathrm{PbI}_{2.55} \mathrm{Br}_{0.45}$ is depicted (light blue), revealing a significantly higher average dipolar coupling than the $\mathrm{MA}_{1-x} \mathrm{FA}_{x} \mathrm{PbI}_{3}$ compositions.

we conclude that average intermolecular proton-proton distances in nearest neighbor coordination are rather similar throughout the investigated compositional range.

Figure 5 (light blue diamond) also shows the experimental average dipolar coupling of $\mathrm{MA}_{0.15} \mathrm{FA}_{0.85} \mathrm{PbI}_{2.55} \mathrm{Br}_{0.45}$. At about $3900 \mathrm{~Hz}$ it is significantly larger than for the binary MA/FA mixtures. Although the lattice contracts slightly upon $\mathrm{Br}^{-}$ incorporation (Table S1), a shrinkage of the pseudocubic lattice constant of about $0.04 \AA$ in comparison to $\mathrm{MA}_{0.25} \mathrm{FA}_{0.75} \mathrm{PbI}_{3}$ and $\alpha-\mathrm{FAPbI}_{3}$ cannot account for an increase in $\bar{D}$ of about $1000 \mathrm{~Hz}$. The increase therefore indicates a restriction in cation mobility either by a significant reduction in reorientation frequency or by a restriction in spatial degrees of freedom, i.e., an anisotropic motion over specific orientations. Stronger interactions of the FA and MA cations with the inorganic sublattice, induced by the presence of more electronegative $\mathrm{Br}^{-}$ions (compared to $\mathrm{I}^{-}$), or the lattice contraction itself could cause this. Both these effects will raise the average dipolar couplings $\bar{D}$ and might give rise to a nonnegligible intramolecular contribution to $\bar{D}$.

These findings fit in a recently proposed scenario of restricted MA cation dynamics upon mixing $\mathrm{I}^{-}$and $\mathrm{Br}^{-}$in the lattice. In this scenario specific hydrogen bonding situations for the MA cations result in a higher activation barrier for rotational jumps in certain directions and thus in their partial immobilization causing an anisotropic dynamical behavior. ${ }^{82}$ For FA cations, however, the hydrogen bonds to the inorganic sublattice are much weaker, ${ }^{26,83}$ initially resulting in faster reorientations in comparison to MA. Consequently, one would expect less influence of $\mathrm{I} / \mathrm{Br}$ mixing on the FA dynamics, which was not resolved in our experiments. To fully understand the origin of the increase of $\bar{D}$ and to characterize the possible dynamical restriction of cations due to interactions with the inorganic sublattice, further MLFF calculations on mixed cation and anion compositions are needed.

Microscopic Cation (Dis)order. The MLFF calculations corroborate that the intramolecular dipolar coupling of the cations is averaged through the rapid reorientation within the A site, and thus only intermolecular dipolar interactions are measured experimentally. Consequently, all ${ }^{1} \mathrm{H}-{ }^{1} \mathrm{H}$ correlations measured in the $2 \mathrm{D}{ }^{1} \mathrm{H}-{ }^{1} \mathrm{H}$ DQSQ MAS NMR spectra (Figure 2) are due to a close proximity of protons on neighboring cations. As we established, the strength of the dipolar interaction only depends on the number of interacting spins and hardly on slight variations of the lattice parameters for the different compositions. Therefore, differences in DQ intensities in the $2 \mathrm{D}$ spectra of the different compounds are directly proportional to the number of intercation interactions, i.e., the relative amounts of MA and FA cations, taking the different numbers of protons for MA and FA into account. The quantitative analysis of the DQ signal intensities thus makes it possible to extract the relative occurrence of each of the intercation dipolar contacts MA-MA, MA-FA, and FA-FA (hereafter referred to as MA-MA, MA-FA, and FA-FA contacts). Their population provides a measure for the microscopic order/disorder of the cations within the perovskite lattice.

In the cubic perovskite lattice, each A site cation, MA or FA, is surrounded by six nearest-neighbor A cations. Different ordering of the cations within the cubic lattice, e.g., random mixing, alternating MA and FA ordering, or clustering of MA or FA cations, results in different probabilities for local nearest neighbor coordinations $\mathrm{MA}\left[\mathrm{MA}_{6-n} \mathrm{FA}_{n}\right]$ and $\mathrm{FA}\left[\mathrm{MA}_{6-n} \mathrm{FA}_{n}\right]$ $(n=1,2, \ldots, 6)$. These are experimentally accessible as the sum of resulting MA-MA, FA-FA, and mixed MA-FA contacts. A random cation distribution can be described by a binomial distribution based on the relative occurrence of MA or FA in 
the lattice, providing the statistics of the total of MA-MA (Figure 2 and Figure 6, green), FA-FA (Figure 2 and Figure 6, blue), and MA-FA contacts (Figure 2 and Figure $6 \mathrm{a}$, red).
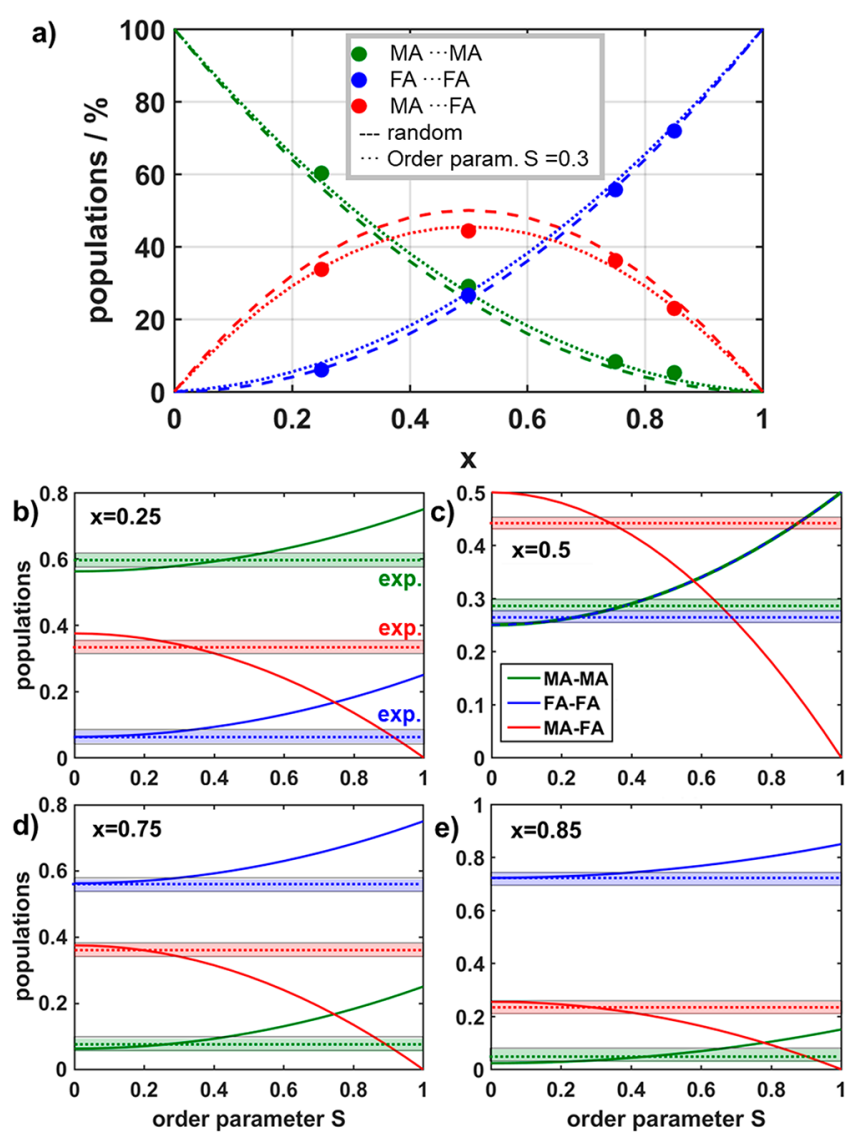

Figure 6. (a) Populations of cation-cation contacts, MA-MA (green), FA-FA (blue), and MA-FA (red), as a function of FA content $\mathrm{x}$. The experimental data are indicated by dots, while the populations according to a random distribution of cations are shown by dashed lines. Dotted lines represent the populations of contacts for a cluster model with an order parameter $S$ of 0.3 . (b-e) Calculated populations of cation-cation contacts, MA-MA (green), FA-FA (blue), and MA-FA (red), as a function of order parameter $S$ for the different compositions of the mixed $\mathrm{MA}_{1-x} \mathrm{FA}_{x} \mathrm{PbI}_{3}(\mathrm{~b}-\mathrm{d})$, as well as $\mathrm{MA}_{0.15} \mathrm{FA}_{0.85} \mathrm{PbI}_{2.55} \mathrm{Br}_{0.45}$ (e). The horizontal bars indicate the experimental accuracy for the observed populations (dashed lines) of cation-cation correlations in the $2 \mathrm{D}{ }^{1} \mathrm{H}-{ }^{1} \mathrm{H}$ DQSQ MAS NMR spectra (Figure 2).

The comparison of the experimentally observed populations (Figure 6a, dots) with the populations resulting for a random distribution (Figure 6a, dashed lines) shows an overall good agreement, with small but systematic deviations especially for the mixed contact MA-FA (red). This indicates a weak tendency for clustering of MA and FA cations, leading to local fluctuations in composition, which can be quantified by introducing an order parameter $S{ }^{84-86}$ in analogy to the analysis of XRD data. ${ }^{87}$ For a cluster model, an order parameter of $S=0$ corresponds to a random distribution, whereas $S=1$ characterizes a complete phase separation. The site occupancies $r_{\mathrm{MA}}$ and $r_{\mathrm{FA}}$ describing the clustering tendency of the cations and thus the local compositional changes can then be parametrized as

$$
r_{\text {MA }}=1-x+S x
$$

$$
r_{\mathrm{FA}}=x+S(1-x)
$$

With that, the theoretical populations for the three cationcation contacts are defined as

$$
\begin{aligned}
& p_{\mathrm{MA}-\mathrm{MA}}=(1-x) r_{\mathrm{MA}}^{2}+x\left(1-r_{\mathrm{FA}}\right)^{2} \\
& p_{\mathrm{FA}-\mathrm{FA}}=x r_{\mathrm{FA}}^{2}+(1-x)\left(1-r_{\mathrm{MA}}\right)^{2} \\
& p_{\mathrm{MA}-\mathrm{FA}}=2\left[x r_{\mathrm{FA}}\left(1-r_{\mathrm{FA}}\right)+(1-x)\left(1-r_{\mathrm{MA}}\right) r_{\mathrm{MA}}\right]
\end{aligned}
$$

Parts $\mathrm{b}-\mathrm{e}$ of Figure 6 depict the calculated populations for the three cation-cation contacts MA-MA (green), FA-FA (blue), and MA-FA (red) as a function of $S$ for different mixed cation compositions $\mathrm{MA}_{1-x} \mathrm{FA}_{x} \mathrm{PbI}_{3}(x=0.25$ (b), $x=$ 0.5 (c), $x=0.75$ (d), $x=0.85$ (e)). Additionally, the experimentally determined occurrence of each contact for each composition $x$ is depicted as dashed lines, where the width of the bars accounts for the experimental error. The intersection of the observed occurrences with the calculated populations reveals that partial MA-MA and FA-FA clustering with an order parameter $S$ between 0.2 and 0.4 takes place for compositions with $x=0.25$ and $x=0.5$. For compositions with higher FA contents $(x=0.75,0.85$, Figure $3 \mathrm{~d}, \mathrm{e})$ the intersection covers a range between $S=0$ and $S=0.3$ for a composition $x=0.75$ and covers a range between $S=0-0.4$ for $x=0.85$. At low and high values of $x$ the changes in populations are less pronounced, preventing a precise assignment of $S$ within the experimental accuracy. Interestingly, the experimentally determined populations show a similar trend over the entire compositional range.

In order to visualize the effect of cation clustering with $S=$ 0.3 in comparison to a random scenario, the distributions of FA (blue) and MA (red) cations for $\mathrm{MA}_{1-x} \mathrm{FA}_{x} \mathrm{PbI}_{3}$ compositions on a $2 \mathrm{D}$ grid are schematically depicted in Figure 7. The circles labeled $r_{\mathrm{MA}}$ and $\mathrm{r}_{\mathrm{FA}}$ demonstrate the local

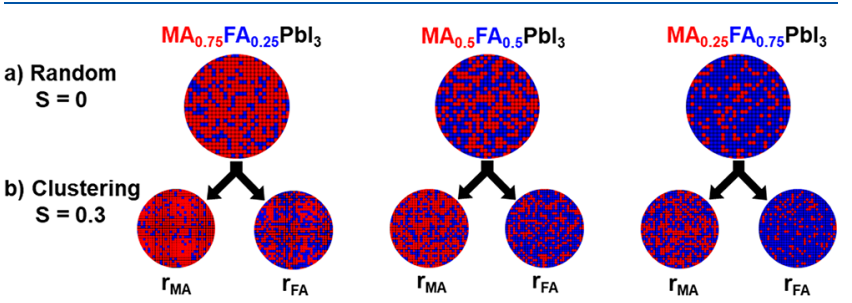

Figure 7. Schematic representation of MA (red)/FA (blue) distributions within $\mathrm{MA}_{1-x} \mathrm{FA}_{x} \mathrm{PbI}_{3}(x=0.25,0.50,0.75)$ perovskites following random statistics (a) and MA or FA clustering (b) to a degree of $S=0.3$ labeled $r_{\mathrm{MA}}$ and $r_{\mathrm{FA}}$, respectively (according to eqs 6 and 7). As the experimental NMR data do not provide information about domain sizes of MA-rich and FA-rich regions, arbitrary sized circles were chosen to represent the statistics.

compositional fluctuations resulting from $\mathrm{MA}$ and $\mathrm{FA}$ clustering, respectively, within the perovskite particles. The schematic representation illustrates that the nominal overall composition $\mathrm{MA}_{1-x} \mathrm{FA}_{x} \mathrm{PbI}_{3}$ is heterogeneous with $\mathrm{MA}$ and FA-rich regions, where the average compositional fluctuations can be described by $r_{\mathrm{MA}}$ and $r_{\mathrm{FA}}$. An upper limit for the size of these clusters is deducted by analyzing the width of the X-ray reflections. Pronounced domains of local compositional fluctuations would lead to the measurement of a distribution of lattice constants and in turn to a broadening of XRD peaks. 
As no broadening is observed (Figure S7), the cluster domains must be smaller than of the order of $100 \mathrm{~nm}$.

To be thermodynamically stable, the Gibbs free energy of the clustered structure must be lower than for the random mix $(S=0)$ structure. In general, the formation of domains results in strain at the domain walls, which is marginal in this particular case, as the pseudocubic lattice constants differ only $0.06 \AA$ between the parent composition $\mathrm{MAPbI}_{3}$ and $\alpha-\mathrm{FAPbI}_{3}$ and $0.03 \AA$ for the mixed compositions $x=0.25$ and $x=0.75$. Furthermore, if the clusters are very small, i.e., in the range of several nearest neighbor shells, domain walls might not even form. If only gradual compositional changes occur, subtle distortions of the inorganic sublattice will be sufficient to compensate for the compositional fluctuations. In a clustered structure, there are less different ways to distribute the cations over the lattice of A sites, resulting in a lower entropy and thus higher free energy. However, the clustering might raise the entropy in case there is an impact on the cation dynamics. Recently it was discussed that the rotational motion of FA cations is confined upon mixing with $\mathrm{MA}^{+}$or $\mathrm{Cs}^{+}$cations because of a preferential orientation of the FA cations. ${ }^{41,43,88}$ As the local configuration of neighboring $\mathrm{MA}^{+}$or $\mathrm{Cs}^{+}$was important for the ordering of $\mathrm{FA},{ }^{43}$ local clustering of MA or FA cations may suppress this reduction of the degrees of motion, thus resulting in a higher dynamical freedom and lowering of the free energy compared to a random mixture.

\section{CONCLUSION}

We have combined NMR spectroscopy and MLFF MD simulations to study the dynamics and local (dis)order of FA and MA cations in the mixed hybrid perovskite systems $\mathrm{MA}_{1-x} \mathrm{FA}_{x} \mathrm{PbI}_{3}$ and $\mathrm{MA}_{0.15} \mathrm{FA}_{0.85} \mathrm{PbI}_{2.55} \mathrm{Br}_{0.45}$. On the basis of our results, we can sketch a plausible scenario for an ordering pattern of the cations in $\mathrm{MA}_{1-x} \mathrm{FA}_{x} \mathrm{PbI}_{3}$ mixed hybrid perovskites. The population analysis of the ${ }^{1} \mathrm{H}-{ }^{1} \mathrm{H}$ DQSQ MAS NMR spectra indicates that a microstructure (order parameter $S \sim 0.3$ ) with MA-rich and FA-rich regions occurs. $\mathrm{XRD}$ analysis indicates that the average size of the domains is below $\sim 100 \mathrm{~nm}$. Furthermore, the novel MLFF method has been shown to accurately predict the average dipolar coupling measured in the NMR experiment. Building on this excellent agreement, we can conclude (a) that the average dipolar coupling $\bar{D}$ is dominated by intermolecular nearest neighbor cation interactions, (b) that it scales with the number of ${ }^{1} \mathrm{H}$ spins on the neighboring cation, which explains its decrease with FA composition $x$, and (c) that it depends on average composition, i.e., we did not observe changes by short-range compositional fluctuations. While a similar $\mathrm{MA}$ and FA ordering was found for the double-mixed $\mathrm{MA}_{0.15} \mathrm{FA}_{0.85} \mathrm{PbI}_{2.55} \mathrm{Br}_{0.45}$ perovskite and the $\mathrm{MA}_{1-x} \mathrm{FA}_{x} \mathrm{PbI}_{3}$ systems, the average ${ }^{1} \mathrm{H}-{ }^{1} \mathrm{H}$ dipolar coupling was observed to be significantly higher in the double-mixed system. This indicates a restriction of the mobility of the organic cations resulting in an anisotropic motion upon incorporation of the smaller $\mathrm{Br}^{-}$ions, possibly induced through the slight lattice contraction. Both these effects will raise the average dipolar coupling $\bar{D}$.

Heterogeneity in local cation compositions results in a local variation of perovskite lattice constants and in local variations of the electrostatic interaction between cations and inorganic sublattice. ${ }^{89,90}$ Both effects cause a distribution of band gap energies of mixed perovskites, as was concluded from the observed distribution of optical properties and $a b$ initio calculations. ${ }^{89,90}$ As a consequence, the charge carriers will localize in energetically favorable domains limiting the overall charge transport. Furthermore, it was found that local compositional heterogeneities can cause the formation of clusters of deep traps. ${ }^{91}$ These trap clusters in turn appear to be the key factor limiting the optoelectronic properties, ${ }^{91}$ ion migration, ${ }^{92,93}$ and stability of mixed halide perovskites. On the basis of these considerations, it appears attractive to reduce the degree of mixing while ensuring a robust stabilization of the perovskite lattice. This indeed is in line with the most recent developments in the field of perovskite solar cells, ${ }^{17}$ where our results will help to better exploit the full potential of mixed halide perovskites and corresponding optoelectronic devices.

\section{ASSOCIATED CONTENT}

\section{(s) Supporting Information}

The Supporting Information is available free of charge at https://pubs.acs.org/doi/10.1021/acs.jpcc.0c10042.

Exact precursor amounts for the syntheses; experimental and calculated average lattice constants of $\mathrm{MA}_{1-x} \mathrm{FA}_{x} \mathrm{PbI}_{3} ;{ }^{13} \mathrm{C}$ SPE MAS NMR spectra, individual ${ }^{1} \mathrm{H}$ DQ buildup curves, exact $\mathrm{MA} / \mathrm{FA}$ ratios and experimental dipolar couplings of $\mathrm{MA}_{1-x} \mathrm{FA}_{x} \mathrm{PbI}_{3}$ and $\mathrm{MA}_{0.15} \mathrm{FA}_{0.85} \mathrm{PbI}_{2.55} \mathrm{Br}_{0.45}$; full $\mathrm{H}-\mathrm{H}$ pair distribution function extracted from $\mathrm{MD}$ simulations; further details on analyses of the MLFF MD simulations (PDF)

\section{AUTHOR INFORMATION}

\section{Corresponding Authors}

Helen Grüninger - Institute for Molecules and Materials, Radboud University, 6525 AJ Nijmegen, The Netherlands; 다이.org/0000-0002-5422-7003; Email: h.gruninger@ science.ru.nl

Menno Bokdam - Faculty of Physics and Center for Computational Materials Sciences, University of Vienna, 1090 Vienna, Austria; Faculty of Science and Technology and MESA+ Institute for Nanotechnology, University of Twente, 7500 AE Enschede, The Netherlands; Email: m.bokdam@ utwente.nl

Arno P. M. Kentgens - Institute for Molecules and Materials, Radboud University, 6525 AJ Nijmegen, The Netherlands; ○ orcid.org/0000-0001-5893-4488; Email: a.kentgens@ nmr.ru.nl

\section{Authors}

Nico Leupold - Department of Functional Materials, University of Bayreuth, 95447 Bayreuth, Germany

Paul Tinnemans - Institute for Molecules and Materials, Radboud University, 6525 AJ Nijmegen, The Netherlands

Ralf Moos - Department of Functional Materials, University of Bayreuth, 95447 Bayreuth, Germany

Gilles A. De Wijs - Institute for Molecules and Materials, Radboud University, 6525 AJ Nijmegen, The Netherlands; (1) orcid.org/0000-0002-1818-0738

Fabian Panzer - Department of Functional Materials and Soft Matter Optoelectronics, University of Bayreuth, 95447 Bayreuth, Germany; (1) orcid.org/0000-0002-2191-9011

Complete contact information is available at:

https://pubs.acs.org/10.1021/acs.jpcc.0c10042

\section{Notes}

The authors declare no competing financial interest. 


\section{ACKNOWLEDGMENTS}

We thank NWO for the support of the "Solid-State NMR Facilities for Advanced Materials Science", which is part of the uNMR-NL ROADMAP facility. The facilities technicians Gerrit Janssen, Hans Janssen, and Ruud Aspers are thanked for their support. H.G. thanks the "Deutsche Forschungsgemeinschaft (DFG)” for funding within Grant GR 5505/1-1. M.B. gratefully thanks Jonathan Lahnsteiner for stimulating discussions on mixed perovskite order. M.B. acknowledges funding by the Austrian Science Fund (FWF): Grant P30316N27. Computations were partly performed on the Vienna Scientific Cluster VSC3. F.P. and N.L. thank the "Deutsche Forschungsgemeinschaft (DFG)" for funding (Project PA $3373 / 3-1)$.

\section{REFERENCES}

(1) NREL. Research Cell Record Efficiency Chart. https://www. nrel.gov/pv/cell-efficiency.html (accessed Sep 30, 2020).

(2) Jena, A. K.; Kulkarni, A.; Miyasaka, T. Halide Perovskite Photovoltaics: Background, Status, and Future Prospects. Chem. Rev. 2019, 119, 3036-3103.

(3) Lin, K.; Xing, J.; Quan, L. N.; de Arquer, F. P. G.; Gong, X.; Lu, J.; Xie, L.; Zhao, W.; Zhang, D.; Yan, C.; et al. Perovskite LightEmitting Diodes with External Quantum Efficiency Exceeding 20 per Cent. Nature 2018, 562, 245-248.

(4) Cho, C.; Zhao, B.; Tainter, G. D.; Lee, J.-Y.; Friend, R. H.; Di, D.; Deschler, F.; Greenham, N. C. The Role of Photon Recycling in Perovskite Light-Emitting Diodes. Nat. Commun. 2020, 11, 611.

(5) Gao, L.; Yan, Q. Recent Advances in Lead Halide Perovskites for Radiation Detectors. Sol. RRL 2020, 4, 1900210.

(6) Wei, H.; Huang, J. Halide Lead Perovskites for Ionizing Radiation Detection. Nat. Commun. 2019, 10, 1066.

(7) Chen, Y.; Yi, H. T.; Wu, X.; Haroldson, R.; Gartstein, Y. N.; Rodionov, Y. I.; Tikhonov, K. S.; Zakhidov, A.; Zhu, X. Y.; Podzorov, V. Extended Carrier Lifetimes and Diffusion in Hybrid Perovskites Revealed by Hall Effect and Photoconductivity Measurements. Nat. Commun. 2016, 7, 12253.

(8) Walsh, A. Principles of Chemical Bonding and Band Gap Engineering in Hybrid Organic-Inorganic Halide Perovskites. J. Phys. Chem. C 2015, 119, 5755-5760.

(9) Jeon, N. J.; Noh, J. H.; Yang, W. S.; Kim, Y. C.; Ryu, S.; Seo, J.; Seok, S. Il. Compositional Engineering of Perovskite Materials for High-Performance Solar Cells. Nature 2015, 517, 476-480.

(10) Petrus, M. L.; Schlipf, J.; Li, C.; Gujar, T. P.; Giesbrecht, N.; Müller-Buschbaum, P.; Thelakkat, M.; Bein, T.; Hüttner, S.; Docampo, P. Capturing the Sun: A Review of the Challenges and Perspectives of Perovskite Solar Cells. Adv. Energy Mater. 2017, 7, 1700264.

(11) Panzer, F.; Li, C.; Meier, T.; Köhler, A.; Huettner, S. Impact of Structural Dynamics on the Optical Properties of Methylammonium Lead Iodide Perovskites. Adv. Energy Mater. 2017, 7, 1700286.

(12) Gao, P.; Grätzel, M.; Nazeeruddin, M. K. Organohalide Lead Perovskites for Photovoltaic Applications. Energy Environ. Sci. 2014, 7, $2448-2463$.

(13) Kazim, S.; Nazeeruddin, M. K.; Grätzel, M.; Ahmad, S. Perovskite as Light Harvester: A Game Changer in Photovoltaics. Angew. Chem., Int. Ed. 2014, 53, 2812-2824.

(14) Park, N.; Grätzel, M.; Miyasaka, T. Organic-Iorganic Halide Perovskite Photovoltaics: From Fundamentals to Devices Architectures; Springer International Publishing: Cham, Switzerland, 2016.

(15) Jeon, N. J.; Na, H.; Jung, E. H.; Yang, T.-Y.; Lee, Y. G.; Kim, G.; Shin, H.-W.; Il Seok, S.; Lee, J.; Seo, J. A Fluorene-Terminated Hole-Transporting Material for Highly Efficient and Stable Perovskite Solar Cells. Nat. Energy 2018, 3, 682-689.

(16) Yang, W. S.; Park, B.; Jung, E. H.; Jeon, N. J.; Kim, Y. C.; Lee, D. U.; Shin, S. S.; Seo, J.; Kim, E. K.; Noh, J. H.; et al. Iodide
Management in Formamidinium-Lead-Halide-Based Perovskite Layers for Efficient Solar Cells. Science 2017, 356, 1376-1379.

(17) Lu, H.; Krishna, A.; Zakeeruddin, S. M.; Grätzel, M.; Hagfeldt, A. Compositional and Interface Engineering of Organic-Inorganic Lead Halide Perovskite Solar Cells. iScience 2020, 23, 101359.

(18) Hoke, E. T.; Slotcavage, D. J.; Dohner, E. R.; Bowring, A. R.; Karunadasa, H. I.; McGehee, M. D. Reversible Photo-Induced Trap Formation in Mixed-Halide Hybrid Perovskites for Photovoltaics. Chem. Sci. 2015, 6, 613-617.

(19) Yang, X.; Yan, X.; Wang, W.; Zhu, X.; Li, H.; Ma, W.; Sheng, C. Light Induced Metastable Modification of Optical Properties in $\mathrm{CH}_{3} \mathrm{NH}_{3} \mathrm{PbI}_{3-\mathrm{x}} \mathrm{Br}_{\mathrm{x}}$ Perovskite Films: Two-Step Mechanism. Org. Electron. 2016, 34, 79-83.

(20) Knight, A. J.; Herz, L. M. Preventing Phase Segregation in Mixed-Halide Perovskites: A Perspective. Energy Environ. Sci. 2020, 13, 2024-2046.

(21) Knight, A. J.; Wright, A. D.; Patel, J. B.; McMeekin, D. P.; Snaith, H. J.; Johnston, M. B.; Herz, L. M. Electronic Traps and Phase Segregation in Lead Mixed-Halide Perovskite. ACS Energy Lett. 2019, 4, 75-84.

(22) Jeong, M.; Choi, I. W.; Go, E. M.; Cho, Y.; Kim, M.; Lee, B.; Jeong, S.; Jo, Y.; Choi, H. W.; Lee, J.; et al. Stable Perovskite Solar Cells with Efficiency Exceeding 24.8\% and 0.3-V Voltage Loss. Science 2020, 369, 1615-1620.

(23) Kim, M.; Kim, G.-H.; Lee, T. K.; Choi, I. W.; Choi, H. W.; Jo, Y.; Yoon, Y. J.; Kim, J. W.; Lee, J.; Huh, D.; et al. Methylammonium Chloride Induces Intermediate Phase Stabilization for Efficient Perovskite Solar Cells. Joule 2019, 3, 2179-2192.

(24) Weller, M. T.; Weber, O. J.; Frost, J. M.; Walsh, A. Cubic Perovskite Structure of Black Formamidinium Lead Iodide, $\alpha$ $\left[\mathrm{HC}\left(\mathrm{NH}_{2}\right)_{2}\right] \mathrm{PbI}_{3}$, at $298 \mathrm{~K}$. J. Phys. Chem. Lett. 2015, 6, 3209-3212.

(25) Weber, O. J.; Charles, B.; Weller, M. T. Phase Behaviour and Composition in the Formamidinium-Methylammonium Hybrid Lead Iodide Perovskite Solid Solution. J. Mater. Chem. A 2016, 4, 1537515382.

(26) Kubicki, D. J.; Prochowicz, D.; Hofstetter, A.; Péchy, P.; Zakeeruddin, S. M.; Grätzel, M.; Emsley, L. Cation Dynamics in Mixed-Cation $(\mathrm{MA})_{\mathrm{x}}(\mathrm{FA})_{1-\mathrm{x}} \mathrm{PbI}_{3}$ Hybrid Perovskites from Solid-State NMR. J. Am. Chem. Soc. 2017, 139, 10055-10061.

(27) Pellet, N.; Gao, P.; Gregori, G.; Yang, T.-Y.; Nazeeruddin, M. K.; Maier, J.; Grätzel, M. Mixed-Organic-Cation Perovskite Photovoltaics for Enhanced Solar-Light Harvesting. Angew. Chem., Int. Ed. 2014, 53, 3151-3157.

(28) Yi, C.; Luo, J.; Meloni, S.; Boziki, A.; Ashari-Astani, N.; Grätzel, C.; Zakeeruddin, S. M.; Röthlisberger, U.; Grätzel, M. Entropic Stabilization of Mixed A-Cation $\mathrm{ABX}_{3}$ Metal Halide Perovskites for High Performance Perovskite Solar Cells. Energy Environ. Sci. 2016, 9, 656-662.

(29) Goldschmidt, V. M. Die Gesetze Der Krystallochemie. Naturwissenschaften 1926, 14, 477-485.

(30) Zhao, J.; Deng, Y.; Wei, H.; Zheng, X.; Yu, Z.; Shao, Y.; Shield, J. E.; Huang, J. Strained Hybrid Perovskite Thin Films and Their Impact on the Intrinsic Stability of Perovskite Solar Cells. Sci. Adv. 2017, 3, No. eaao5616.

(31) Zhu, C.; Niu, X.; Fu, Y.; Li, N.; Hu, C.; Chen, Y.; He, X.; Na, G.; Liu, P.; Zai, H.; et al. Strain Engineering in Perovskite Solar Cells and Its Impacts on Carrier Dynamics. Nat. Commun. 2019, 10, 815.

(32) Motta, C.; El-Mellouhi, F.; Kais, S.; Tabet, N.; Alharbi, F.; Sanvito, S. Revealing the Role of Organic Cations in Hybrid Halide Perovskite $\mathrm{CH}_{3} \mathrm{NH}_{3} \mathrm{PbI}_{3}$. Nat. Commun. 2015, 6, 7026.

(33) Gong, J.; Yang, M.; Ma, X.; Schaller, R. D.; Liu, G.; Kong, L.; Yang, Y.; Beard, M. C.; Lesslie, M.; Dai, Y.; et al. Electron-Rotor Interaction in Organic-Inorganic Lead Iodide Perovskites Discovered by Isotope Effects. J. Phys. Chem. Lett. 2016, 7, 2879-2887.

(34) Jesper Jacobsson, T.; Correa-Baena, J.-P. P.; Pazoki, M.; Saliba, M.; Schenk, K.; Grätzel, M.; Hagfeldt, A. Exploration of the Compositional Space for Mixed Lead Halogen Perovskites for High Efficiency Solar Cells. Energy Environ. Sci. 2016, 9, 1706-1724. 
(35) Zheng, X.; Wu, C.; Jha, S. K.; Li, Z.; Zhu, K.; Priya, S. Improved Phase Stability of Formamidinium Lead Triiodide Perovskite by Strain Relaxation. ACS Energy Lett. 2016, 1, 1014-1020.

(36) Xie, L. Q.; Chen, L.; Nan, Z. A.; Lin, H. X.; Wang, T.; Zhan, D. P.; Yan, J. W.; Mao, B. W.; Tian, Z. Q. Understanding the Cubic Phase Stabilization and Crystallization Kinetics in Mixed Cations and Halides Perovskite Single Crystals. J. Am. Chem. Soc. 2017, 139, $3320-3323$.

(37) Tennyson, E. M.; Doherty, T. A. S.; Stranks, S. D. Heterogeneity at Multiple Length Scales in Halide Perovskite Semiconductors. Nat. Rev. Mater. 2019, 4, 573-587.

(38) Alanazi, A. Q.; Kubicki, D. J.; Prochowicz, D.; Alharbi, E. A.; Bouduban, M. E. F.; Jahanbakhshi, F.; Mladenović, M.; Milić, J. V.; Giordano, F.; Ren, D.; et al. Atomic-Level Microstructure of Efficient Formamidinium-Based Perovskite Solar Cells Stabilized by 5Ammonium Valeric Acid Iodide Revealed by Multinuclear and Two-Dimensional Solid-State NMR. J. Am. Chem. Soc. 2019, 141, 17659-17669.

(39) Kubicki, D. J.; Prochowicz, D.; Hofstetter, A.; Saski, M.; Yadav, P.; Bi, D.; Pellet, N.; Lewiński, J.; Zakeeruddin, S. M.; Grätzel, M.; et al. Formation of Stable Mixed Guanidinium-Methylammonium Phases with Exceptionally Long Carrier Lifetimes for High-Efficiency Lead Iodide-Based Perovskite Photovoltaics. J. Am. Chem. Soc. 2018, 140, 3345-3351.

(40) Kubicki, D. J.; Prochowicz, D.; Hofstetter, A.; Zakeeruddin, S. M.; Gratzel, M.; Emsley, L. Phase Segregation in Cs-, Rb- and KDoped Mixed-Cation (MA) $)_{\mathrm{x}}(\mathrm{FA})_{1-\mathrm{x}} \mathrm{PbI}_{3}$ Hybrid Perovskites from Solid-State NMR. J. Am. Chem. Soc. 2017, 139, 14173-14180.

(41) Ghosh, D.; Smith, A. R.; Walker, A. B.; Islam, M. S. Mixed ACation Perovskites for Solar Cells: Atomic-Scale Insights into Structural Distortion, Hydrogen Bonding, and Electronic Properties. Chem. Mater. 2018, 30, 5194-5204.

(42) Van Gompel, W. T. M.; Herckens, R.; Reekmans, G.; Ruttens, B.; D'Haen, J.; Adriaensens, P.; Lutsen, L.; Vanderzande, D. Degradation of the Formamidinium Cation and the Quantification of the Formamidinium-Methylammonium Ratio in Lead Iodide Hybrid Perovskites by Nuclear Magnetic Resonance Spectroscopy. J. Phys. Chem. C 2018, 122, 4117-4124.

(43) Fisicaro, G.; La Magna, A.; Alberti, A.; Smecca, E.; Mannino, G.; Deretzis, I. Local Order and Rotational Dynamics in Mixed ACation Lead Iodide Perovskites. J. Phys. Chem. Lett. 2020, 11, 10681074.

(44) Franssen, W. M. J.; Kentgens, A. P. M. Solid - State NMR of Hybrid Halide Perovskites. Solid State Nucl. Magn. Reson. 2019, 100, 36-44.

(45) Wasylishen, R. E.; Knop, O.; Macdonald, J. B. Cation Rotation in Methylammonium Lead Halides. Solid State Commun. 1985, 56, $581-582$.

(46) Knop, O.; Wasylishen, R. E.; White, M. A.; Cameron, T. S.; Van Oort, M. J. M. Alkylammonium Lead Halides. Part 2. $\mathrm{CH}_{3} \mathrm{NH}_{3} \mathrm{PbX}_{3}$ $(\mathrm{X}=\mathrm{Cl}, \mathrm{Br}, \mathrm{I})$ Perovskites: Cuboctahedral Halide Cages with Isotropic Cation Reorientation. Can. J. Chem. 1990, 68, 412-422.

(47) Bernard, G. M.; Wasylishen, R. E.; Ratcliffe, C. I.; Terskikh, V.; Wu, Q.; Buriak, J. M.; Hauger, T. Methylammonium Cation Dynamics in Methylammonium Lead Halide Perovskites: A SolidState NMR Perspective. J. Phys. Chem. A 2018, 122, 1560-1573.

(48) Franssen, W. M. J.; Bruijnaers, B. J.; Portengen, V. H. L.; Kentgens, A. P. M. Dimethylammonium Incorporation in Lead Acetate Based $\mathrm{MAPbI}_{3}$ Perovskite Solar Cells. ChemPhysChem 2018, $19,3107-3115$.

(49) Franssen, W. M. J.; Van Es, S. G. D.; Dervişoğlu, R.; de Wijs, G. A.; Kentgens, A. P. M. Symmetry, Dynamics, and Defects in Methylammonium Lead Halide Perovskites. J. Phys. Chem. Lett. 2017, 8, 61-66.

(50) Roiland, C.; Trippé-Allard, G.; Jemli, K.; Alonso, B.; Ameline, J.-C. C.; Gautier, R.; Bataille, T.; Le Pollès, L.; Deleporte, E.; Even, J.; et al. Multinuclear NMR as a Tool for Studying Local Order and Dynamics in $\mathrm{CH}_{3} \mathrm{NH}_{3} \mathrm{PbX}_{3}(\mathrm{X}=\mathrm{Cl}, \mathrm{Br}, \mathrm{I})$ Hybrid Perovskites. Phys. Chem. Chem. Phys. 2016, 18 (39), 27133-27142.
(51) Martineau, C.; Senker, J.; Taulelle, F. NMR Crystallography. Annu. Rep. NMR Spectrosc. 2014, 82, 1-57.

(52) Harris, R. K.; Wasylishen, R. E.; Duer, M. J. NMRCrystallography; Wiley: Chichester, U.K., 2009.

(53) Charpentier, T. The PAW/GIPAW Approach for Computing NMR Parameters: A New Dimension Added to NMR Study of Solids. Solid State Nucl. Magn. Reson. 2011, 40, 1-20.

(54) Moran, R. F.; Dawson, D. M.; Ashbrook, S. E. Exploiting NMR Spectroscopy for the Study of Disorder in Solids. Int. Rev. Phys. Chem. 2017, 36, 39-115.

(55) Grüninger, H.; Schmutzler, A.; Siegel, R.; Armstrong, K.; Frost, D. J.; Senker, J. Quantitative Description of ${ }^{1} \mathrm{H}$ SQ and DQ Coherences for the Hydroxyl Disorder within Hydrous Ringwoodite. Phys. Chem. Chem. Phys. 2018, 20, 15098-15105.

(56) Moran, R. F.; McKay, D.; Pickard, C. J.; Berry, A. J.; Griffin, J. M.; Ashbrook, S. E. Hunting for Hydrogen: Random Structure Searching and Prediction of NMR Parameters of Hydrous Wadsleyite. Phys. Chem. Chem. Phys. 2016, 18, 10173-10181.

(57) Jinnouchi, R.; Lahnsteiner, J.; Karsai, F.; Kresse, G.; Bokdam, M. Phase Transitions of Hybrid Perovskites Simulated by MachineLearning Force Fields Trained on the Fly with Bayesian Inference. Phys. Rev. Lett. 2019, 122, 225701.

(58) Lahnsteiner, J.; Jinnouchi, R.; Bokdam, M. Long-Range Order Imposed by Short-Range Interactions in Methylammonium Lead Iodide: Comparing Point-Dipole Models to Machine-Learning Force Fields. Phys. Rev. B: Condens. Matter Mater. Phys. 2019, 100, 094106.

(59) Grüninger, H.; Armstrong, K.; Greim, D.; Boffa-Ballaran, T.; Frost, D. J.; Senker, J. Hidden Oceans? Unraveling the Structure of Hydrous Defects in the Earth's Deep Interior. J. Am. Chem. Soc. 2017, 139 (30), 10499-10505.

(60) Saalwächter, K. Robust NMR Approaches for the Determination of Homonuclear Dipole-Dipole Coupling Constants in Studies of Solid Materials and Biomolecules. ChemPhysChem 2013, 14, 3000-3014.

(61) Brown, S. P. Probing Proton-Proton Proximities in the Solid State. Prog. Nucl. Magn. Reson. Spectrosc. 2007, 50, 199-251.

(62) Leupold, N.; Schötz, K.; Cacovich, S.; Bauer, I.; Schultz, M.; Daubinger, M.; Kaiser, L.; Rebai, A.; Rousset, J.; Köhler, A.; et al. High Versatility and Stability of Mechanochemically Synthesized Halide Perovskite Powders for Optoelectronic Devices. ACS Appl. Mater. Interfaces 2019, 11, 30259-30268.

(63) Fung, B. M.; Khitrin, A. K.; Ermolaev, K. An Improved Broadband Decoupling Sequence for Liquid Crystals and Solids. J. Magn. Reson. 2000, 142, 97-101.

(64) Saalwächter, K.; Lange, F.; Matyjaszewski, K.; Huang, C.-F.; Graf, R. BaBa-Xy16: Robust and Broadband Homonuclear DQ Recoupling for Applications in Rigid and Soft Solids up to the Highest MAS Frequencies. J. Magn. Reson. 2011, 212, 204-215.

(65) Bartók, A. P.; Payne, M. C.; Kondor, R.; Csányi, G. Gaussian Approximation Potentials: The Accuracy of Quantum Mechanics, without the Electrons. Phys. Rev. Lett. 2010, 104, 136403.

(66) Bartók, A. P.; Kondor, R.; Csányi, G. On Representing Chemical Environments. Phys. Rev. B: Condens. Matter Mater. Phys. 2013, 87, 184115.

(67) Jinnouchi, R.; Karsai, F.; Kresse, G. On-the-Fly Machine Learning Force Field Generation: Application to Melting Points. Phys. Rev. B: Condens. Matter Mater. Phys. 2019, 100, 014105.

(68) Kresse, G.; Furthmüller, J. Efficiency of Ab-Initio Total Energy Calculations for Metals and Semiconductors Using a Plane-Wave Basis Set. Comput. Mater. Sci. 1996, 6, 15-50.

(69) Kresse, G.; Furthmüller, J. Efficient Iterative Schemes for Ab Initio Total-Energy Calculations Using a Plane-Wave Basis Set. Phys. Rev. B: Condens. Matter Mater. Phys. 1996, 54, 11169-11186.

(70) Sun, J.; Ruzsinszky, A.; Perdew, J. P. Strongly Constrained and Appropriately Normed Semilocal Density Functional. Phys. Rev. Lett. 2015, 115, 036402.

(71) Bokdam, M.; Lahnsteiner, J.; Ramberger, B.; Schäfer, T.; Kresse, G. Assessing Density Functionals Using Many Body Theory for Hybrid Perovskites. Phys. Rev. Lett. 2017, 119, 145501. 
(72) Blöchl, P. E. Projector Augmented-Wave Method. Phys. Rev. B: Condens. Matter Mater. Phys. 1994, 50, 17953-17979.

(73) Goc, R. Effective Spatial Averaging for NMR Second Moment Calculation. J. Magn. Reson. 1998, 132, 78-80.

(74) Goc, R. Calculation of the NMR Second Moment for Materials with Different Types of Internal Rotation. Solid State Nucl. Magn. Reson. 1998, 13, 55-61.

(75) Goc, R. Computer Calculation of the Van Vleck Second Moment for Materials with Internal Rotation of Spin Groups. Comput. Phys. Commun. 2004, 162, 102-112.

(76) Karmakar, A.; Askar, A. M.; Bernard, G. M.; Terskikh, V. V.; Ha, M.; Patel, S.; Shankar, K.; Michaelis, V. K. Mechanochemical Synthesis of Methylammonium Lead Mixed-Halide Perovskites: Unraveling the Solid-Solution Behavior Using Solid-State NMR. Chem. Mater. 2018, 30, 2309-2321.

(77) Askar, A. M.; Wiltshire, B. D.; Patel, S.; Fleet, J.; Shankar, K.; Karmakar, A.; Bernard, G. M.; Ha, M.; Michaelis, V. K.; Terskikh, V. V.; et al. Composition-Tunable Formamidinium Lead Mixed Halide Perovskites via Solvent-Free Mechanochemical Synthesis: Decoding the Pb Environments Using Solid-State NMR Spectroscopy. J. Phys. Chem. Lett. 2018, 9, 2671-2677.

(78) Aebli, M.; Piveteau, L.; Nazarenko, O.; Benin, M. B.; Krieg, F.; Verel, R.; Kovalenko, M. V. Lead-Halide Scalar Couplings in Pb NMR of $\mathrm{APbX}_{3}$ Perovskites $(\mathrm{A}=\mathrm{Cs}$, Methylammonium, Formamidinium ; $\mathrm{X}=\mathrm{Cl}, \mathrm{Br}, \mathrm{I})$. Sci. Rep. 2020, 10, 8229.

(79) Rosales, B. A.; Men, L.; Cady, S. D.; Hanrahan, M. P.; Rossini, A. J.; Vela, J. Persistent Dopants and Phase Segregation in Organolead Mixed-Halide Perovskites. Chem. Mater. 2016, 28, 6848-6859.

(80) Zorin, V. E.; Brown, S. P.; Hodgkinson, P. Quantification of Homonuclear Dipolar Coupling Networks from Magic-Angle Spinning ${ }^{1}$ H NMR. Mol. Phys. 2006, 104, 293-304.

(81) Bradley, J. P.; Tripon, C.; Filip, C.; Brown, S. P. Determining Relative Proton-Proton Proximities from the Build-up of TwoDimensional Correlation Peaks in ${ }^{1} \mathrm{H}$ Double-Quantum MAS NMR: Insight from Multi-Spin Density-Matrix Simulations. Phys. Chem. Chem. Phys. 2009, 11, 6941-6952.

(82) Selig, O.; Sadhanala, A.; Müller, C.; Lovrincic, R.; Chen, Z.; Rezus, Y. L. A.; Frost, J. M.; Jansen, T. L. C.; Bakulin, A. A. Organic Cation Rotation and Immobilization in Pure and Mixed Methylammonium Lead-Halide Perovskites. J. Am. Chem. Soc. 2017, 139, 4068-4074.

(83) Svane, K. L.; Forse, A. C.; Grey, C. P.; Kieslich, G.; Cheetham, A. K.; Walsh, A.; Butler, K. T. How Strong Is the Hydrogen Bond in Hybrid Perovskites? J. Phys. Chem. Lett. 2017, 8, 6154-6159.

(84) Knijn, P. J.; van Bentum, P. J. M.; van Eck, E. R. H.; Fang, C.; Grimminck, D. L. A. G.; de Groot, R. A.; Havenith, R. W. A.; Marsman, M.; Meerts, W. L.; De Wijs, G. A.; et al. A Solid-State NMR and DFT Study of Compositional Modulations in $\mathrm{Al}_{\mathrm{x}} \mathrm{Ga}_{1-\mathrm{x}} \mathrm{As}$. Phys. Chem. Chem. Phys. 2010, 12, 11517-11535.

(85) Tycko, R.; Dabbagh, G.; Kurtz, S. R.; Goral, J. P. Quantitative Study of Atomic Ordering in $\mathrm{Ga}_{0.5} \mathrm{In}_{0.5} \mathrm{P}$ Thin Films by P31 Nuclear Magnetic Resonance. Phys. Rev. B: Condens. Matter Mater. Phys. 1992, $45,13452-13457$.

(86) Degen, C.; Tomaselli, M.; Meier, B. H.; Voncken, M. M. A. J.; Kentgens, A. P. M. NMR Investigation of Atomic Ordering in $\mathrm{Al}_{\mathrm{x}} \mathrm{Ga}_{1-\mathrm{x}} \mathrm{As}$ Thin Films. Phys. Rev. B: Condens. Matter Mater. Phys. 2004, 69, 1-4.

(87) Cullity, B. D. Elements of X-Ray Diffraction, 2nd ed.; Addison Wesley: Reading, MA, 1978.

(88) Mozur, E. M.; Hope, M. A.; Trowbridge, J. C.; Halat, D. M.; Daemen, L. L.; Maughan, A. E.; Prisk, T. R.; Grey, C. P.; Neilson, J. R. Cesium Substitution Disrupts Concerted Cation Dynamics in Formamidinium Hybrid Perovskites. Chem. Mater. 2020, 32, 62666277.

(89) Chatterjee, R.; Pavlovetc, I. M.; Aleshire, K.; Hartland, G. V.; Kuno, M. Subdiffraction Infrared Imaging of Mixed Cation Perovskites: Probing Local Cation Heterogeneities. ACS Energy Lett. 2018, 3, 469-475.
(90) Maheshwari, S.; Patwardhan, S.; Schatz, G. C.; Renaud, N.; Grozema, F. C. The Effect of the Magnitude and Direction of the Dipoles of Organic Cations on the Electronic Structure of Hybrid Halide Perovskites. Phys. Chem. Chem. Phys. 2019, 21, 16564-16572.

(91) Doherty, T. A. S.; Winchester, A. J.; Macpherson, S.; Johnstone, D. N.; Pareek, V.; Tennyson, E. M.; Kosar, S.; Kosasih, F. U.; Anaya, M.; Abdi-Jalebi, M.; et al. Performance-Limiting Nanoscale Trap Clusters at Grain Junctions in Halide Perovskites. Nature 2020, 580, $360-366$

(92) Tong, C.-J.; Geng, W.; Prezhdo, O. V.; Liu, L.-M. Role of Methylammonium Orientation in Ion Diffusion and Current-Voltage Hysteresis in the $\mathrm{CH}_{3} \mathrm{NH}_{3} \mathrm{PbI}_{3}$ Perovskite. ACS Energy Lett. 2017, 2, 1997-2004.

(93) Huang, Y.; Li, L.; Liu, Z.; Jiao, H.; He, Y.; Wang, X.; Zhu, R.; Wang, D.; Sun, J.; Chen, Q.; et al. The Intrinsic Properties of $\mathrm{FA}_{(1-\mathrm{x})} \mathrm{MA}_{\mathrm{x}} \mathrm{PbI}_{3}$ Perovskite Single Crystals. J. Mater. Chem. A 2017, 5 (18), 8537-8544. 